\title{
Impact of Desensitization on Antiviral Immunity in HLA-Sensitized Kidney Transplant Recipients
}

\author{
Mieko Toyoda, ${ }^{1}$ Bong-Ha Shin, ${ }^{1}$ Shili Ge, ${ }^{1}$ James Mirocha, ${ }^{2}$ David Thomas, \\ Maggie Chu, ${ }^{1}$ Edgar Rodriguez, ${ }^{1}$ Christine Chao, ${ }^{1}$ Anna Petrosyan, ${ }^{1}$ Odette A. Galera, ${ }^{1}$ \\ Ashley Vo, ${ }^{3}$ Jua Choi, ${ }^{3}$ Alice Peng, ${ }^{3}$ Joseph Kahwaji, ${ }^{3}$ and Stanley C. Jordan ${ }^{3}$ \\ ${ }^{1}$ Transplant Immunology Laboratory, Cedars-Sinai Medical Center, Los Angeles, CA, USA \\ ${ }^{2}$ Biostatistics Core, Cedars-Sinai Medical Center, Los Angeles, CA, USA \\ ${ }^{3}$ Comprehensive Transplant Center, Cedars-Sinai Medical Center, Los Angeles, CA, USA
}

Correspondence should be addressed to Mieko Toyoda; mieko.toyoda@cshs.org

Received 17 October 2016; Accepted 15 December 2016; Published 6 February 2017

Academic Editor: Mepur H. Ravindranath

Copyright (C) 2017 Mieko Toyoda et al. This is an open access article distributed under the Creative Commons Attribution License, which permits unrestricted use, distribution, and reproduction in any medium, provided the original work is properly cited.

Viral infections represent significant morbidity and mortality factors in kidney transplant recipients, with CMV, EBV, and BKV infections being most common. Desensitization (DES) with IVIg and rituximab with/without plasma exchange followed by kidney transplantation with alemtuzumab induction increased successful transplant rates in HLA-sensitized patients but may represent an increased risk for viral infections due to severe lymphocyte depletion. Here, we report on the posttransplant viral infection status in 372 DES versus 538 non-DES patients. CMV and EBV viremia were significantly lower in DES patients, while BKV viremia was similar. This trend was observed primarily in CMV sero(-), EBV sero(+), and sero(-) patients. No patient developed PTLD. The incidence of BKAN, allograft, and patient survival was similar in both groups. These viral infections were not associated with subsequent allograft rejection which occurred within 6 months after the infection. Conclusions. The IVIg + rituximab desensitization combined with alemtuzumab induction with triple immunosuppression maintenance does not increase the risk for $\mathrm{CMV}, \mathrm{EBV}$, and BKV infections. Possible factors include, in addition to posttransplant antiviral prophylaxis and PCR monitoring, presence of memory T cells and antibodies specific to CMV and likely EBV, NK cell-mediated ADCC despite lymphocyte depletion, elimination of EBV and CMV reservoirs by rituximab and alemtuzumab, and use of IVIg with antiviral properties.

\section{Introduction}

Viral infections represent significant morbidity and mortality factors for immunocompromised transplant recipients $[1,2]$. Cytomegalovirus (CMV) and Epstein-Barr virus (EBV) infections are common and have long been associated with significant morbidity in the renal transplant population [1-5]. Polyomavirus BK (BKV) also emerged as an important viral infection associated with risk for allograft loss. $[6,7]$. The most common manifestations of CMV infection include flu-like or mononucleosis-like syndromes, leukopenia or thrombocytopenia, infection of native tissues resulting in pneumonia, gastroenteritis, retinitis, and central nerve system disease [4]. Posttransplant lymphoproliferative disorder (PTLD) is one of the most serious complications in transplant recipients and is usually associated with EBV infection $[3,8]$. PTLD is a consequence of the failure of the host's immune system to contain EBV-infected B cells, resulting in uncontrolled proliferation. BKV establishes latency in the uroepithelium and persists in the renal tubules without causing disease in immunocompetent individuals $[9,10]$. However, BKV reactivation occurring in renal transplant recipients may cause an acute tubulointerstitial nephritis and ureteral stenosis, leading to severe allograft dysfunction and graft loss $[6,7,11]$.

We have shown that desensitization (DES) with intravenous immunoglobulin (IVIg) and rituximab with/without plasma exchange (PLEX) followed by a kidney transplantation with alemtuzumab induction increased successful transplant rates in HLA-sensitized (HS) patients [12-15]. 
TABle 1: Patient demographics.

\begin{tabular}{|c|c|c|c|}
\hline \multirow{2}{*}{ Demographics } & \multicolumn{2}{|c|}{ Kidney transplant patients } & \multirow{2}{*}{$p$ value } \\
\hline & DES group $(n=372)$ & Non-DES group $(n=538)$ & \\
\hline Transplant date & $1 / 4 / 07-4 / 18 / 15$ & $1 / 10 / 07-4 / 17 / 15$ & \\
\hline Age, mean \pm SD & $49.6 \pm 13.3$ & $51.1 \pm 14.2$ & 0.11 \\
\hline Gender (female), $n(\%)$ & $226(60.8)$ & $157(29.2)$ & $\leq \mathbf{0 . 0 0 1}$ \\
\hline Race, $n(\%)$ & & & 0.27 \\
\hline African-American & $69 / 368(18.8)$ & $84 / 499(16.8)$ & \\
\hline Hispanic & $101 / 368(27.4)$ & $167 / 499(33.5)$ & \\
\hline White & $148 / 368(40.2)$ & $180 / 499(36.1)$ & \\
\hline Others & $50 / 368(13.6)$ & $68 / 499(13.6)$ & \\
\hline Living donor transplant, $n(\%)$ & $141(37.9)$ & $177(32.9)$ & 0.12 \\
\hline Induction, $n(\%)$ & & & $\leq \mathbf{0 . 0 0 1}$ \\
\hline Lymphocyte depletion & $312 / 365(85.5)$ & $241 / 496(48.6)$ & \\
\hline Anti-IL-2 receptor & $53 / 365(14.5)$ & $255 / 496(51.4)$ & \\
\hline Maintenance (tacrolimus), $n(\%)$ & $351 / 354(99.2)$ & $452 / 493(91.7)$ & $\leq \mathbf{0 . 0 0 1}$ \\
\hline HLA match ${ }^{*}$, mean \pm SD & $1.9 \pm 1.6$ & $1.9 \pm 1.7$ & 0.78 \\
\hline $\mathrm{PRA}, n(\%)$ & & & $\leq 0.001$ \\
\hline$>10 \%$ & $66(17.7)$ & $470(87.3)$ & \\
\hline $10-80 \%$ & $113(30.4)$ & $68(12.7)$ & \\
\hline$>80 \%$ & $193(51.9)$ & $0(0)$ & \\
\hline \multicolumn{4}{|l|}{ Reason for DES, $n(\%)$} \\
\hline HS & $314(84.4)$ & na & \\
\hline $\mathrm{HS} / \mathrm{ABOi}$ & $17(4.6)$ & na & \\
\hline ABOi & $41(11.0)$ & na & \\
\hline Recipient with CMV sero(-) at Tx, $n(\%)$ & $57 / 368(15.5)$ & $140 / 524(26.7)$ & $\leq \mathbf{0 . 0 0 1}$ \\
\hline Recipient with EBV sero(-) at Tx, $n(\%)$ & $13 / 361(3.6)$ & $33 / 486(6.8)$ & $\underline{0.04}$ \\
\hline Follow-up (months post-Tx) ${ }^{* *}$, mean $\pm \mathrm{SD}$ & $24.4 \pm 20.3$ & $24.6 \pm 20.1$ & 0.84 \\
\hline Sample number tested for viral-PCR/patient, mean \pm SD & $9.7 \pm 5.2$ & $9.5 \pm 7.4$ & 0.61 \\
\hline
\end{tabular}

${ }^{*}$ HLA match in 350 DES and 392 non-DES patients with available results. ${ }^{* *}$ Follow-up for viral-PCR monitoring.

The number of patients with available results was provided if not available in all the patients. PRA: panel reactive antibody, DES: desensitization, HS: HLAsensitization, $\mathrm{ABOi}$ : $\mathrm{ABO}$ incompatible transplantation, and Tx: transplant.

We have also shown acceptable outcomes in patients who received $\mathrm{ABO}$ incompatible transplants after the modified DES protocol with IVIg, rituximab, and PLEX [12]. However, profound and prolonged $\mathrm{B}$ cell and $\mathrm{T}$ cell depletion may result in an increased risk for viral infections [16-22]. To address this, all these patients receive antiviral prophylaxis posttransplant and extensive viral-PCR monitoring to minimize viral infections and their associated complications by early detection and intervention. We have previously shown that DES patients do not exhibit a significant increased risk for viral infection compared to non-DES patients $[15,23-$ 26], except for a significantly higher BKV infection rate in DES patients [27]. In this study, we investigated the status of $\mathrm{CMV}, \mathrm{EBV}$, and BKV viral infection and their associated complication in a much larger cohort of patients who received DES and the results were compared with those without DES (non-DES). We also investigated the impact of viral infection on allograft rejection, since an association has been suggested that viral infections may increase this risk through direct effects on allograft-directed immune responses or due to reduced immunosuppression at time of infections. [28-30]. Here, we found significantly lower CMV and EBV infection rates in DES patients and similar BKV infection rates. We then investigated patient and graft survival and immune factors possibly responsible for these findings.

\section{Materials and Methods}

This study was approved by the Institutional Review Board at Cedars-Sinai Medical Center (IRB numbers Pro00017197, 10969, and 12562). The study was conducted in accordance with the ethical guideline based on federal regulations and the common rule. CSMC also has a Federal Wide Assurance.

2.1. Patient Population and Healthy Volunteers. CMV, EBV, and/or BKV-PCR results in a total of 3614 and 5113 DNA samples obtained from 372 DES and 538 non-DES patients, respectively, were compared. We also examined graft and patient survival, pretransplant viral serological status, virusassociated complication, and allograft rejection. Patients examined were transplanted between January 2007 and April 2015 at Cedars-Sinai Medical Center with patient demographics shown in Table 1. Patients who were $<18$ years old, 
were monitored for viral-PCRs $<2.9$ months after transplant, or had <3 DNA samples obtained during the viral-PCR monitoring period (median 8.0 DNA samples per patient during median 18.7 months after transplant) were excluded.

Of 372 DES patients, $314(84.4 \%)$ received an $\mathrm{ABO}$ compatible and $58(15.6 \%)$ an $\mathrm{ABO}$ incompatible kidney transplant after DES. The DES protocols used for ABO compatible transplant in $\mathrm{HS}$ and $\mathrm{ABO}$ incompatible transplant in non-HS patients have been reported [12]. Briefly, a standard protocol for HLA-DES consisted of 2 doses of IVIg $(2 \mathrm{~g} / \mathrm{kg})$ one month apart with one dose of rituximab $(1 \mathrm{~g})$ in between. The protocol for $\mathrm{ABO}$ incompatible transplant consisted of one dose of rituximab $(1 \mathrm{~g})$ two weeks prior to initiation of 5-7 sessions of PLEX followed by one dose of IVIg $(2 \mathrm{~g} / \mathrm{kg})$. The combination of both protocols was used for HS patients who received an $\mathrm{ABO}$ incompatible transplant. If a negative or acceptable crossmatch was achieved and/or the antiblood group titer became $\leq 1: 8$ after DES, patients proceeded to transplantation $[14,15]$.

Most patients received induction therapy with lymphocyte depleting agent (alemtuzumab or anti-thymocyte globulin) or anti-IL-2 receptor antibody (anti-IL-2R, daclizumab, or basiliximab). Maintenance immunosuppression consisted of calcineurin inhibitor (tacrolimus or cyclosporine A), mycophenolate mofetil (MMF), and steroids. The target levels were dependent on the type of induction as reported elsewhere [27].

All patients received antiviral prophylaxis with ganciclovir $(1.25 \mathrm{mg} / \mathrm{kg}$ daily) while inpatient and then valganciclovir or acyclovir posttransplant depending on a risk for viral infection. For transplants with CMV R-/D+, 900 mg valganciclovir was given daily for 6 months regardless of induction type. For those with lymphocyte depletion induction, $450 \mathrm{mg}$ valganciclovir was given daily for 6 months for CMV R+/D+, $\mathrm{R}+/ \mathrm{D}-$, or $\mathrm{R}-/ \mathrm{D}-$. For those with anti-IL-2R induction, $800 \mathrm{mg}$ acyclovir was given $4 \mathrm{x}$ a day for CMV $\mathrm{R}+/ \mathrm{D}+$ or $\mathrm{R}+/ \mathrm{D}-$ and $800 \mathrm{mg}$ daily for CMV R-/D- for 3-6 months, with dose adjustment for renal function and/or white blood cell count. CMV-, EBV-, and/or BKV-PCR monitoring was performed at 1, 2, 3, 6, 9, 12,18, and 24 months after transplant or as needed as previously reported [23], and every two weeks in those who developed viremia. CMV and EBV infections were treated with reduction of immunosuppression in conjunction with valganciclovir $(900 \mathrm{mg}$ twice daily for 14 to 21 days, regardless of infection during or after antiviral prophylaxis with dose adjustments for renal function and/or white blood cell count). BKV was treated with reduction of immunosuppression, leflunomide, and/or IVIg. Antibodymediated (ABMR) and cell-mediated (CMR) rejections were diagnosed based on the Banff 2013 [31, 32] and Banff 1997 classification [33], respectively. ABMR was treated with pulse steroids, IVIg and rituximab with or without PLEX, and CMR with pulse steroids. Refractory or Banff 2a rejection was treated with ATG.

Of 372 DES patients, 36 were monitored for lymphocyte subset analysis before and after transplant by flow cytometry, and archived sera obtained from another 38 patients were tested for total IgG and anti-EBV-IgG before and after transplant by ELISA.
Heparinized-peripheral blood samples from 20 normal adult volunteers ( 7 males) were tested for CMV- and EBVspecific $\mathrm{T}$ cell and NK cell activity.

2.2. Viral-PCR Assays. Viral-PCR was performed at the Transplantation and Immunology Laboratory, Cedars-Sinai Medical Center [23, 27, 34]. Briefly, for CMV- and EBV-PCR, total DNA was extracted from blood leukocytes by Qiacube (Qiagen, Valencia, CA) followed by optical density measurement, and 500 ng total DNA was submitted for the real time CMV- and EBV-PCR. CMV and EBV > 5 copies/PCR (500 ng total DNA) were considered viremia. For BKV-PCR, total DNA was extracted from $200 \mu \mathrm{l}$ of plasma and eluted in $100 \mu \mathrm{l}$ of Tris-EDTA; $10 \mu \mathrm{l}$ of the DNA solution was used for the real time BKV-PCR [27]. The result was expressed as BKV DNA copies/ml plasma and $>250$ copies $/ \mathrm{ml}$ was considered viremia. Specific primers and probe used were as follows: for the CMV-PCR, specific to the CMV immediate-early antigen region ( $5^{\prime}$-CAA GCG GCC TCT GAT AAC CA- $3^{\prime}, 5^{\prime}$-ACT AGG AGA GCA GAC TCT CAG AGG AT- $3^{\prime}, 5^{\prime}$-FAM-TGC ATG AAG GTC TTT GCC CAG TAC ATT CT-BHQ- ${ }^{\prime}$ ) [35], for the EBV-PCR, specific to the BALF5 gene encoding the viral DNA polymerase of human EBV $\left(5^{\prime}\right.$ CGG AAG CCC TCT GGA CTT C $3^{\prime}, 5^{\prime}$ CCC TGT TTA TCC GAT GGA ATG $3^{\prime}, 5^{\prime}$ FAM-TGT ACA CGC ACG AGA AAT GCG CCBHQ $3^{\prime}$ ) [36], and for the BKV-PCR, specific to the large T antigen of human BKV ( $5^{\prime}$-AAA GTC TTT AGG GTC TTC TAC CTT TCT TT- $3^{\prime}, 5^{\prime}$-GAG TCC TGG TGG AGT TCC TTT AAT- $3^{\prime}, 5^{\prime}$-FAM-AAT CTG CTG TTG CTT CTT CAT CAC TGG CA-BHQ- $3^{\prime}$ ) and designed by our laboratory.

2.3. Lymphocyte Cell Subset Analysis. The CD4+, CD8+ T cell, CD19+ B cell, and CD56+/CD16+ NK cell numbers were monitored for DES patients before and after transplant by flow cytometry using a standard 6-color direct staining method as previously described with minor modification $[37,38]$. Briefly, $5 \mu \mathrm{l}$ each of the fluorochrome-conjugated antibodies to CD45 (Horizon V500, BD Biosciences, San Jose, CA), CD3 (FITC, Invitrogen), CD8 (Horizon V450, BD Biosciences), CD56 (APC, BD Biosciences), CD16 (PerCPCy5.5, eBioscience, San Diego, CA), and CD19 (PE-Cy7, eBioscience) was added to $100 \mu \mathrm{l}$ of heparinized blood. $\mathrm{CD} 45+$ cells were first separated and then plotted against forward/side scatter to separate lymphocytes. Lymphocytes were then plotted against $\mathrm{CD} 3$ and $\mathrm{CD} 8, \mathrm{CD} 3-$ population was further plotted against CD19 to enumerate CD19+ B cell number, and the remaining cells plotted against CD16 and CD56. CD56+/CD16+, CD56+/CD16-, and CD56-/CD16+ were considered NK cells (CD56+/CD16+ cells). CD3+/CD8- cells were considered as $\mathrm{CD} 4+$ cells.

2.4. $C M V$ - or EBV-Specific T Helper (CMV-or EBV-Th) and NK (CMV- or EBV-NK) Cell Analysis. CMV- or EBV-Th and NK cell levels were measured by intracellular cytokine flow cytometry (CFC) developed in our lab and described elsewhere with minor modification [39-41]. Briefly, whole blood was incubated with sucrose density purified CMV or EBV viral lysate (Advanced Biotechnologies, Eldersburg, $\mathrm{MD}$ ) at the final concentration of $1 \mu \mathrm{g} / \mathrm{ml}$, together with 
brefeldin A and anti-CD28/CD49d overnight. After cells were stained with fluorochrome-conjugated antibodies to CD45 (V500), CD3 (FITC), CD4 (PerCP-Cy5.5), CD8 (V450), and CD56 (APC) and then with PE-anti-IFN $\gamma$ antibody for intracellular IFN $\gamma$ staining, followed by cell acquisition, the IFN $\gamma+$ cell\% in CD4+ T cells and CD56+ NK cells were enumerated and defined as CMV-Th or EBV-Th and CMVNK or EBV-NK, respectively. CMV-Th $\geq 0.20 \%$, EBV-Th $\geq 0.10 \%$, and CMV- and EBV-NK $\geq 0.5 \%$ were considered positive as established based on the levels detected in CMV or EBV sero(+) and sero(-) normal individuals and transplant recipients $[37,39,40]$. Phytohemagglutinin (PHA) at the final concentration of $1 \mu \mathrm{g} / \mathrm{ml}$ was used as positive control for each sample tested. In a separate experiment where degranulation in CMV- or EBV-T and NK cells was assessed, PE-Cy7conjugated anti-CD107a antibody was also added, and the IFN $\gamma+$ cell\% and CD107a + cell\% in CD4+ T cells and CD56+ NK cells were enumerated. To assess the involvement of anti-CMV antibody in NK cell activation, whole blood was first incubated with IdeS (Hansa Medical, Sweden), an IgGdegrading enzyme of $S$. pyogenes, that cleaves 4 human IgG subclasses at the hinge region of $\operatorname{IgG}$ heavy chains, critical for ADCC [42], at the final concentration of $10 \mu \mathrm{g} / \mathrm{ml}$ at $37^{\circ} \mathrm{C}$ for 1 hour, and then incubated with CMV lysate to continue the above CFC procedure.

2.5. Total IgG- and Anti-EBV IgG-ELISA. Total IgG (Human IgG-ELISA, Bethyl Laboratories, Inc. Montgomery, TX) and anti-EBV IgG levels (EBV-VCA IgG-ELISA, Calbiotech, El Cajon, CA) were measured by ELISA following the manufacturers' instruction. In the total IgG-ELISA, the results were expressed as $\mathrm{mg} / \mathrm{ml}$, and the levels $>7,4-7$ and $<4 \mathrm{mg} / \mathrm{ml}$ were considered normal, mild, and severe hypogammaglobulinemia [43], respectively. In the anti-EBV IgG-ELISA, the results were expressed as anti-EBV IgG index and the index $<0.25$ was considered EBV sero(-).

2.6. Statistical Analysis. We compared the results in the DES versus non-DES groups, viral sero(+) versus sero(-) groups, or different antiviral prophylaxis groups (Tables 16 ). Continuous variables were analyzed using Student's $t$ test and categorical variables were analyzed by Chi-square or Fisher's exact test unless otherwise stated. Total IgG and anti-EBV IgG levels before DES versus 12 months after transplant (Figure 4) and IFN $\gamma+$ or CD107a+ cell\% in CD4+ $\mathrm{T}$ or CD56+ NK cells between conditions (Figure 6) were compared by paired $t$-test. The rates of CMV, EBV, or BKV viremia, allograft rejection, allograft loss, and patient death were estimated by the Kaplan-Meier method and the group differences were assessed by the log-rank test. The $p$ value $<$ 0.05 was considered statistically significant.

\section{Results and Discussion}

3.1. Baseline Characteristics. Baseline characteristics in DES and non-DES patients are shown in Table 1. All 372 DES patients showed PRA $>10 \%$ and 193 of those (52\%) had PRA $>80 \%$ before DES. Among DES patients, $314(84 \%)$ received DES for HLA incompatibility, while 41 (11\%) and $17(5 \%)$ received DES for ABOi or ABOi + HLA incompatibilities, respectively. There were significantly more females $(61 \%$ versus $29 \%, p<0.001)$, more lymphocyte depletion induction ( $86 \%$ versus $49 \%, p<0.001)$, and maintenance with tacrolimus ( $99 \%$ versus $92 \%, p<0.001$ ) in the DES group. More female patients are HLA-sensitized due to pregnancy, and lymphocyte depletion induction and tacrolimus were used as a standard posttransplant immunosuppressive regimen for DES patients. It should be noted that $96 \%$ of DES patients induced with a lymphocyte depleting agent received alemtuzumab, while $81 \%$ of non-DES patients received ATG. Significantly more non-DES patients showed CMV $(27 \%$ versus $16 \%, p<0.001)$ and EBV (7\% versus $4 \%, p=0.04)$ negative serology at transplant. Transplant date, age, race, living donor transplant, HLA match, viral-PCR monitoring follow-up period, and sample number tested for viral-PCR per patient were similar in both groups.

3.2. The Immune Cell Number before and after Transplant in DES and Non-DES Patients. CD8+, CD4+ T cell, CD19+ B cell, and CD56+/CD16+ NK cell number before DES and after transplant in 36 DES patients are shown in Figure 1. CD19+ $B$ cells were nearly undetectable after rituximab treatment during the DES and continued to be low for several months [39]. For patients receiving alemtuzumab induction after rituximab, the levels at 1 month after transplant (after alemtuzumab) were nearly undetectable (Figure 1(c)). Recovery of CD19+ B cells began 2-3 months after transplant. Although most patients still showed $<30 \%$ of the pre-DES levels of $\mathrm{CD} 19+\mathrm{B}$ cells at 6 months after transplant, rapid repopulation was also observed in some patients as previously reported by others [44]. The number of $\mathrm{T}$ cells significantly decreased after alemtuzumab induction and restoration began 2-3 months after transplant. It should be noted that the CD4+ $\mathrm{T}$ cell numbers at 1 month after transplant were nearly undetectable in most patients (Figure 1(b)), while the CD8+ cell numbers were $1-10 \%$ of pre-DES levels (Figure 1(a)). The CD8+ cell number continued to be higher than that of CD4+ cells afterward, which was consistent with our previous report [37]. This trend is likely due to $\mathrm{CD} 4+\mathrm{T}$ cells being more sensitive than CD8+ $\mathrm{T}$ cells to alemtuzumab depletion [45] and/or CD8+ $\mathrm{T}$ cell restoration being more rapid than CD4+ $\mathrm{T}$ cells [46]. In contrast to $\mathrm{B}$ cells and $\mathrm{T}$ cells, the reduction of NK cell numbers after transplant was minimal; $20-50 \%$ of pre-DES levels were already observed at 1 month after transplant and most patients showed $>50 \%$ of pre-DES levels by 3 months after transplant (Figure 1(d)). This is consistent with previous observations that NK cells were less susceptible to alemtuzumab depletion [47] and NK cell repopulation was faster than $T$ cells in alemtuzumab-treated cynomolgus monkeys [48].

Alemtuzumab is a monoclonal antibody, targeting CD52 positive cells such as mature lymphocytes, including $\mathrm{T}$ cell, B cell, NK cells, and monocytes, and then depleting them [49]. On the other hand, another lymphocyte depleting agent, ATG, is a polyclonal antibody prepared from the sera of rabbits or horses immunized with thymocytes. ATG primarily depletes T cells [19], although induction of B cell apoptosis by ATG was reported [50], resulting in slight reduction of $B$ 
TABLE 2: CMV, EBV, and BKV viremia in DES and non-DES patients.

\begin{tabular}{|c|c|c|c|}
\hline \multirow{2}{*}{ Viral DNA detected } & \multicolumn{2}{|c|}{ Kidney transplant patients } & \multirow{2}{*}{$p$ value } \\
\hline & DES group $(n=372)$ & Non-DES group $(n=538)$ & \\
\hline \multicolumn{4}{|l|}{ CMV-PCR > 5.0 copies/PCR } \\
\hline Viremia rate $(\% \pm \mathrm{SE})^{*}$ & $30.3 \pm 3.6$ & $35.7 \pm 2.9$ & 0.19 \\
\hline 1st viremia (m post-Tx) & $5.8 \pm 10.3$ & $7.7 \pm 14.1$ & 0.23 \\
\hline Peak levels (copies/PCR) & $420 \pm 1077$ & $2730 \pm 18374$ & 0.12 \\
\hline Duration $(\mathrm{m})$ & $0.7 \pm 0.7$ & $1.1 \pm 2.0$ & $\underline{0.02}$ \\
\hline \multicolumn{4}{|l|}{ CMV-PCR > 30 copies/PCR } \\
\hline Vremia rate $(\% \pm \mathrm{SE})^{*}$ & $16.1 \pm 2.1$ & $25.2 \pm 2.7$ & $\underline{0.04}$ \\
\hline 1st viremia (m post-Tx) & $3.7 \pm 4.0$ & $6.7 \pm 12.5$ & $\underline{0.02}$ \\
\hline Peak levels (copies/PCR) & $699 \pm 1331$ & $3904 \pm 21887$ & 0.13 \\
\hline Duration $(\mathrm{m})$ & $0.8 \pm 0.5$ & $1.4 \pm 2.4$ & $\underline{0.01}$ \\
\hline \multicolumn{4}{|l|}{ CMV-PCR > 50 copies/PCR } \\
\hline Viremia rate $(\% \pm \mathrm{SE})^{*}$ & $13.5 \pm 1.9$ & $22.5 \pm 2.7$ & $\leq 0.05$ \\
\hline 1st viremia (m post-Tx) & $3.4 \pm 3.1$ & $7.1 \pm 13.3$ & $\underline{0.01}$ \\
\hline Peak levels (copies/PCR) & $811 \pm 1410$ & $4462 \pm 23360$ & 0.13 \\
\hline Duration $(\mathrm{m})$ & $0.8 \pm 0.6$ & $1.5 \pm 2.5$ & $\underline{0.01}$ \\
\hline \multicolumn{4}{|l|}{ EBV-PCR $>5.0$ copies/PCR } \\
\hline Viremia rate $(\% \pm \mathrm{SE})^{*}$ & $13.6 \pm 3.8$ & $30.0 \pm 4.5$ & $\leq \mathbf{0 . 0 0 1}$ \\
\hline 1st viremia (m post-Tx) & $18.8 \pm 19.5$ & $13.1 \pm 19.3$ & 0.20 \\
\hline Peak levels (copies/PCR) & $171 \pm 512$ & $74 \pm 141$ & 0.36 \\
\hline Duration $(\mathrm{m})$ & $6.7 \pm 17.5$ & $4.5 \pm 6.4$ & 0.54 \\
\hline \multicolumn{4}{|l|}{ EBV-PCR > 30 copies/PCR } \\
\hline Viremia rate $(\% \pm \mathrm{SE})^{*}$ & $2.9 \pm 1.1$ & $11.3 \pm 2.8$ & $\underline{0.001}$ \\
\hline 1st viremia (m post-Tx) & $14.5 \pm 20.2$ & $9.4 \pm 15.5$ & 0.52 \\
\hline Peak levels (copies/PCR) & $474 \pm 785$ & $157 \pm 187$ & 0.29 \\
\hline Duration $(\mathrm{m})$ & $17.1 \pm 26.6$ & $7.5 \pm 7.7$ & 0.34 \\
\hline \multicolumn{4}{|l|}{ EBV-PCR > 50 copies/PCR } \\
\hline Viremia rate $(\% \pm \mathrm{SE})^{*}$ & $2.3 \pm 1.0$ & $6.4 \pm 1.5$ & $\underline{0.01}$ \\
\hline 1st viremia (m post-Tx) & $9.4 \pm 7.8$ & $6.4 \pm 8.4$ & $\overline{0.47}$ \\
\hline Peak levels (copies/PCR) & $691 \pm 884$ & $216 \pm 205$ & 0.29 \\
\hline Duration $(\mathrm{m})$ & $23.6 \pm 30.6$ & $8.3 \pm 8.1$ & 0.32 \\
\hline PTLD, $n(\%)$ & 0 & 0 & na \\
\hline \multicolumn{4}{|l|}{ BKV-PCR > 250 copies/ml } \\
\hline Viremia rate $(\% \pm \mathrm{SE})^{*}$ & $20.1 \pm 2.5$ & $17.1 \pm 1.9$ & 0.21 \\
\hline 1st viremia (m post-Tx) & $5.2 \pm 5.4$ & $6.6 \pm 8.7$ & 0.25 \\
\hline Peak levels (copies/PCR) & $7.2 \times 10^{5} \pm 4.3 \times 10^{6}$ & $1.6 \times 10^{5} \pm 5.8 \times 10^{5}$ & 0.31 \\
\hline Duration $(\mathrm{m})$ & $5.0 \pm 10.4$ & $5.8 \pm 11.1$ & 0.70 \\
\hline \multicolumn{4}{|l|}{ BKV-PCR >1500 copies/ml } \\
\hline Viremia rate $(\% \pm \mathrm{SE})^{*}$ & $11.2 \pm 1.8$ & $13.0 \pm 1.8$ & 0.72 \\
\hline 1st viremia (m post-Tx) & $4.2 \pm 4.0$ & $6.4 \pm 9.7$ & 0.14 \\
\hline Peak levels (copies/PCR) & $1.2 \times 10^{6} \pm 5.5 \times 10^{6}$ & $2.1 \times 10^{5} \pm 6.6 \times 10^{5}$ & 0.28 \\
\hline Duration $(\mathrm{m})$ & $7.8 \pm 12.8$ & $7.3 \pm 12.2$ & 0.84 \\
\hline \multicolumn{4}{|l|}{ BKV-PCR >2500 copies/ml } \\
\hline Viremia rate $(\% \pm \mathrm{SE})^{*}$ & $10.9 \pm 1.8$ & $10.7 \pm 1.7$ & 0.60 \\
\hline 1st viremia (m post-Tx) & $4.3 \pm 4.1$ & $6.9 \pm 10.6$ & 0.12 \\
\hline Peak levels (copies/PCR) & $1.3 \times 10^{6} \pm 5.6 \times 10^{6}$ & $2.5 \times 10^{5} \pm 7.2 \times 10^{5}$ & 0.30 \\
\hline Duration $(\mathrm{m})$ & $8.0 \pm 13.0$ & $8.4 \pm 13.2$ & 0.88 \\
\hline
\end{tabular}


TABLE 2: Continued.

\begin{tabular}{lccc}
\hline Viral DNA detected & \multicolumn{2}{c}{ Kidney transplant patients } & $p$ value \\
& DES group $(n=372)$ & Non-DES group $(n=538)$ & $10(1.9)$ \\
BKAN, $n(\%)$ & $4(1.1)$ & $11.6 \pm 7.1$ & 0.35 \\
Time for BKAN (m post-Tx) & $12.3 \pm 10.1$ & 0.92 \\
\hline
\end{tabular}

${ }^{*}$ The viremia rates $(\% \pm$ standard error [SE]) at 5 years after transplant $(\mathrm{Tx})$ were estimated by the Kaplan-Meier method and the group differences were assessed by the log-rank test.

Results for 1st viremia, peak levels, duration, and time for BKAN are mean \pm standard deviation.

$m$ post-Tx: months after transplant, PTLD: posttransplant lymphoproliferative disorder, and BKAN: BKV-associated nephropathy.

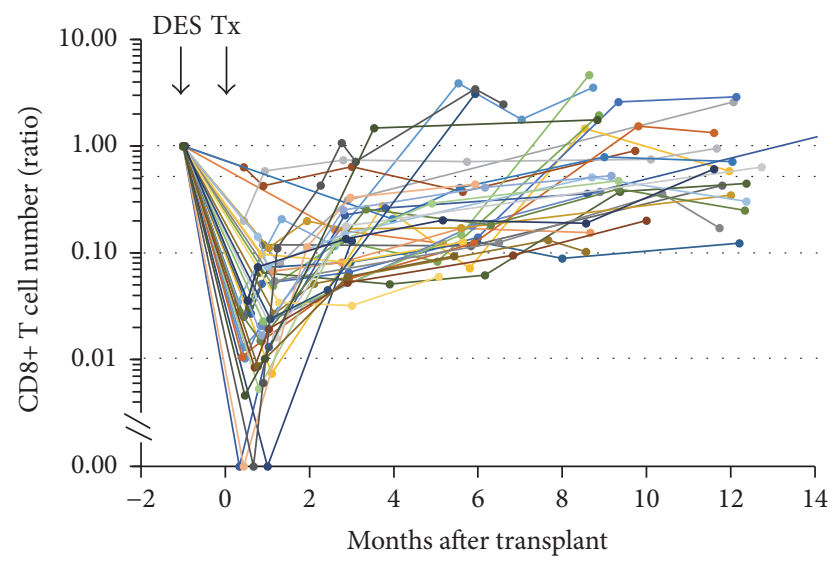

(a) CD8+ T cells

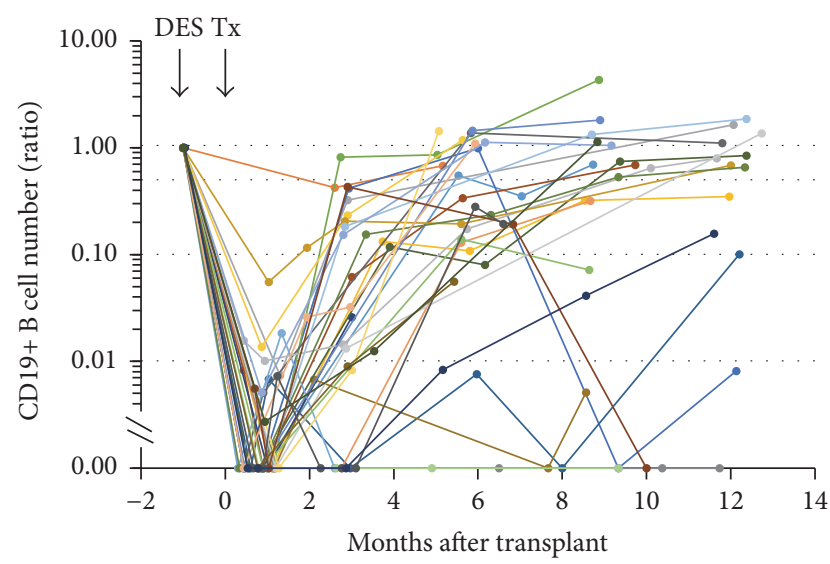

(c) $\mathrm{CD} 19+\mathrm{B}$ cells

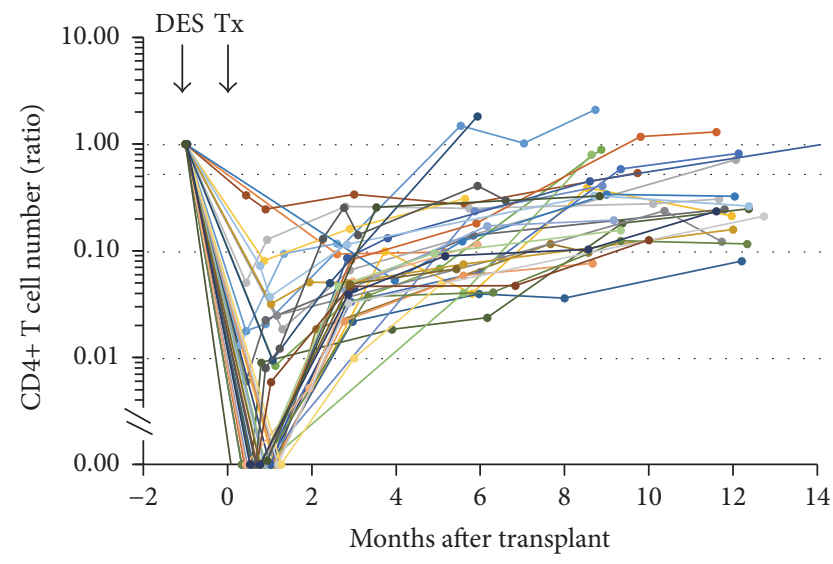

(b) CD4+ T cells

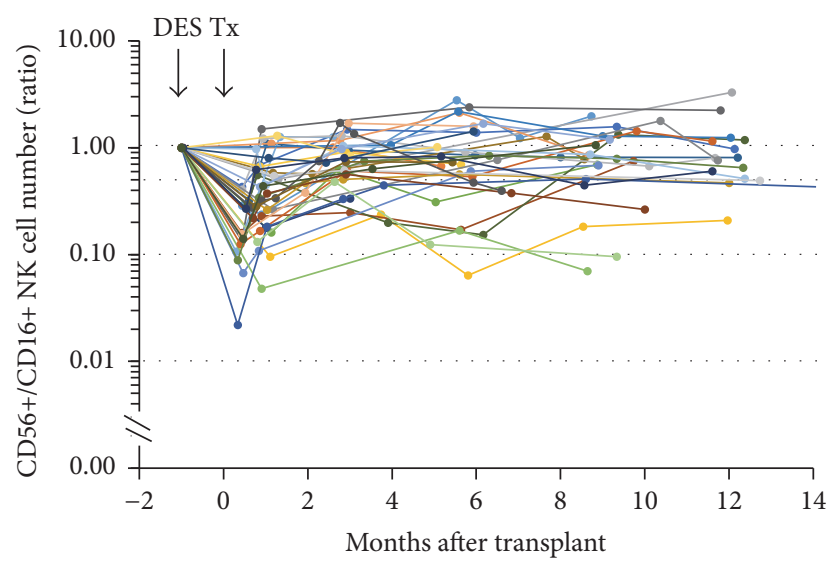

(d) $\mathrm{CD} 56+/ \mathrm{CD} 16+\mathrm{NK}$ cells

FIgure 1: The number of CD8+ (a), CD4+ T cells (b), CD19+ B cells (c), and CD56+/CD16+ NK cells (d) pre-DES and posttransplant in 36 DES patients who received DES with IVIg + rituximab followed by a kidney transplant with alemtuzumab induction. Each line with each symbol describes the result from one patient. The results were expressed as the ratio against the pre-DES level in each patient. DES: desensitization; Tx: transplant.

cells after ATG induction [51]. However, alemtuzumab was reported to be more powerful in reducing T cells than ATG preparations, while reduction of NK cells was similar [51]. In this study, $86 \%$ of DES and $49 \%$ of non-DES patients received lymphocyte depleting agents, and, of these, 96\% of DES patients received alemtuzumab, while $81 \%$ of nonDES received ATG. Considering additional $\mathrm{B}$ cell depletion by rituximab and alemtuzumab, $\mathrm{B}$ cell and $\mathrm{T}$ cell depletion in DES was more intense compared to non-DES patients. Theoretically, this should increase the risk for infections in
DES patients. Thus, we investigated the viral infection status in DES versus non-DES patients.

3.3. Viral Infection in DES and Non-DES Patients. CMV, EBV, and BKV viremia status after transplant in 372 DES and 538 non-DES patients are summarized in Table 2. CMV or EBV DNA levels $>5$ copies/PCR and BKV DNA levels > 250 copies/ $\mathrm{ml}$ as analyzed by our viral-PCR assays were considered viremia, and the levels $>50$ copies/PCR and $>2500$ copies $/ \mathrm{ml}$, respectively, were usually considered for antiviral 


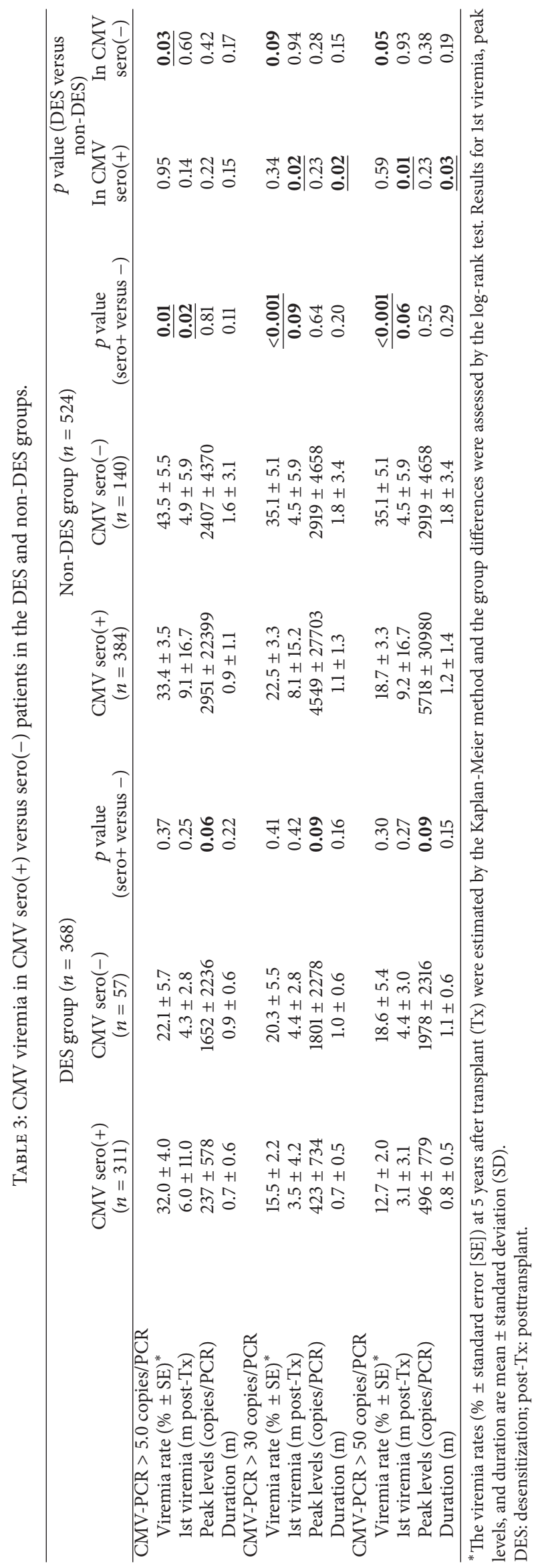




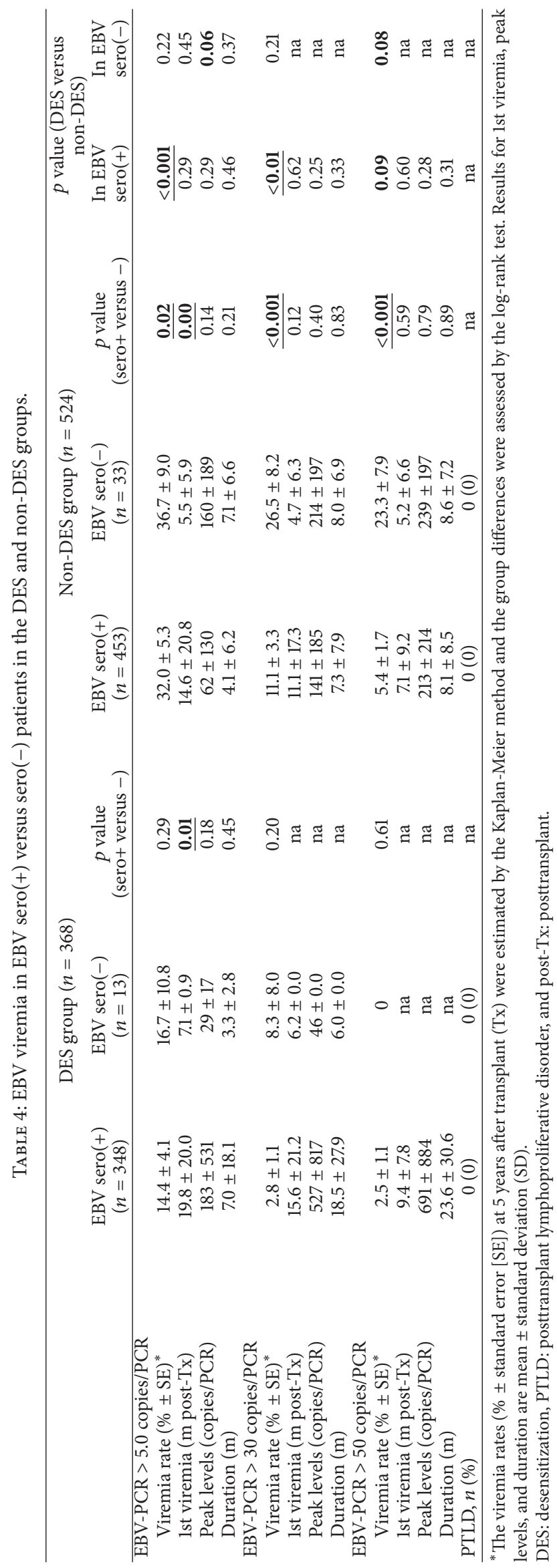




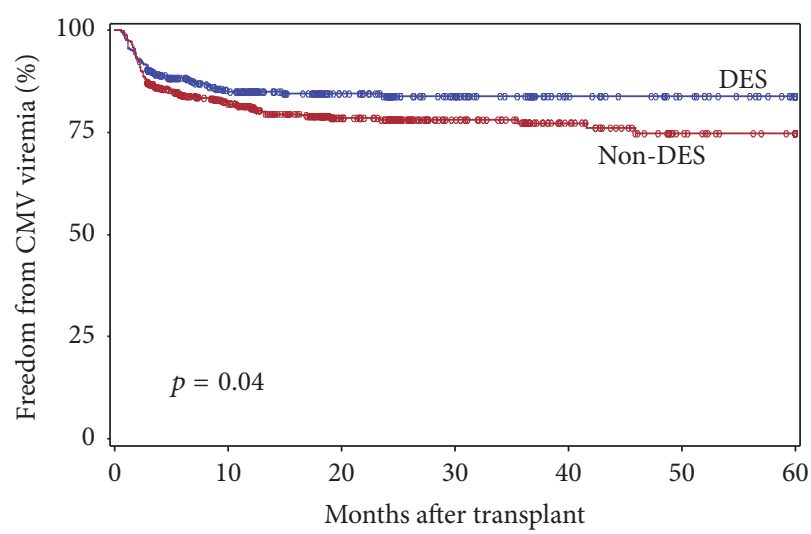

(a) CMV viremia with $>30$ copies/PCR

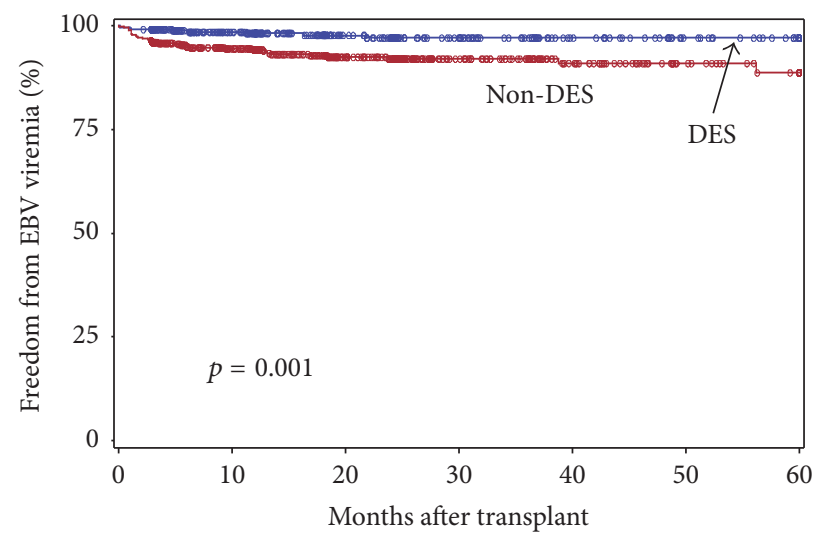

(b) EBV viremia with $>30$ copies/PCR

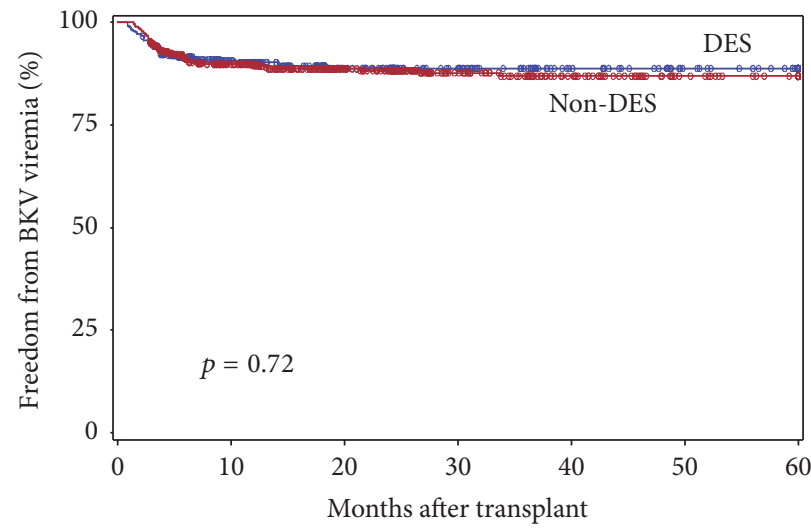

(c) BKV viremia with $>1500$ copies $/ \mathrm{ml}$

Figure 2: Freedom from CMV (a) or EBV (b) viremia with $>30$ copies/PCR and BKV (c) viremia with $>1500$ copies/ml in DES (blue) and non-DES (red) patients during the 1st 5 years after transplant. The group differences were assessed by the log-rank test.

TABLE 5: CMV and EBV viremia in sero(+) non-DES patients who received valganciclovir (VGCV-LD) versus acyclovir prophylaxis (ACV-anti-IL-2R).

\begin{tabular}{lc}
\hline Patients & Number of patients (\%) \\
\hline CMV sero(+) non-DES & w/CMV-PCR $>30$ copies/PCR \\
VGCV-LD $(n=176)$ & $31(17.6)$ \\
ACV-anti-IL-2R $(n=175)$ & $26(14.9)$ \\
\hline VGCV-LD-ATZ $(n=25)$ & $7(28.0)$ \\
VGCV-LD-ATG $(n=151)$ & $24(15.9)$ \\
\hline & \\
\hline EBV sero $(+)$ non-DES & $22(11.0)$ \\
VGCV-LD $(n=200)$ & $6(2.8)^{*}$ \\
ACV-anti-IL-2R $(n=215)$ & $2(5.1)$ \\
\hline VGCV-LD-ATZ $(n=39)$ & $20(12.4)$ \\
VGCV-LD-ATG $(n=161)$ & w/EBV-PCR $>30$ copies/PCR \\
\hline
\end{tabular}

VGCV: valganciclovir; ACV: acyclovir.

LD: lymphocyte depletion; anti-IL-2R: anti-IL-2 receptor.

ATZ: alemtuzumab; ATG: anti-thymocyte globulin.

${ }^{*} p<0.001$ versus VGCV-LD by Fisher's exact test.

therapy. Patients with CMV or EBV DNA levels between 30 and 50 copies/PCR and with BKV levels between 1500 and
2500 copies/ml may or may not be treated with antiviral therapy depending on other factors. Thus, the viremia status in the two groups was compared based on 3 viral-PCR cutoff levels. Due to early detection and early intervention, most patients with viremia were asymptomatic.

Freedom from CMV or EBV viremia with $>30$ copies/PCR and BKV viremia with $>1500$ copies $/ \mathrm{ml}$ in the DES versus non-DES groups is shown in Figure 2, and the CMV, EBV, or BKV viremia rates with 3 cutoff levels are shown in Table 2. One of the most striking findings in this analysis was the significantly lower CMV and EBV viremia rates in the DES group except for $\mathrm{CMV}$ viremia with $>5$ copies/PCR, and there was no difference in the BKV viremia rates (Table 2, Figure 2). Estimated viremia rates at 5 years after transplant were $30 \%$ versus $36 \%(p=0.19), 16 \%$ versus $25 \%(p=0.04)$, and $14 \%$ versus $23 \%(p<0.05)$ for $\mathrm{CMV}$ viremia with $>5,>30$ and $>50$ copies/PCR, respectively; $14 \%$ versus $30 \%(p<0.001), 2.9 \%$ versus $11 \%(p=0.001)$, and $2.3 \%$ versus $6.4 \%(p=0.01)$ for EBV viremia with $>5,>30$, and $>50$ copies/PCR, respectively. Significantly shorter duration of CMV viremia (mean months 0.7 versus $1.1[p=0.02$ ] 0.8 versus $1.4[p=0.01]$, and 0.8 versus 1.5 $[p=0.01]$ for viremia with $>5,>30$, and $>50$ copies $/ P C R$, resp.) and the trend of lower CMV DNA peak levels were also observed in the DES compared to non-DES group. The 
TABLE 6: Viral infection and allograft rejection (AR) in DES and non-DES patients.

\begin{tabular}{|c|c|c|c|}
\hline \multirow{2}{*}{ Allograft rejection (AR) } & \multicolumn{2}{|c|}{ Kidney transplant patients } & \multirow{2}{*}{$p$ value $^{* *}$} \\
\hline & DES group $(n=363)$ & Non-DES group $(n=497)$ & \\
\hline \multicolumn{4}{|l|}{$\mathrm{AR}, n(\%)$} \\
\hline Any AR & $68(18.7)$ & $70(14.1)$ & 0.07 \\
\hline ABMR & $44(12.1)$ & $11(2.2)$ & $\leq 0.001$ \\
\hline CMR & $41(11.3)$ & $68(13.7)$ & 0.35 \\
\hline $\mathrm{CMV}, \mathrm{EBV}$, or BKV viremia*,$n(\%)$ & $80(22.0)$ & $138(27.8)$ & 0.06 \\
\hline \multicolumn{4}{|l|}{ AR within 6 months after VI, $n(\%)$} \\
\hline Any AR after VI & $15 / 80(18.8)$ & $16 / 138(11.6)$ & 0.16 \\
\hline ABMR after VI & $8 / 80(10.0)$ & $3 / 138(2.2)$ & $\underline{0.02}$ \\
\hline CMR after VI & $11 / 80(13.8)$ & $15 / 138(10.9)$ & 0.52 \\
\hline
\end{tabular}

${ }^{*}$ Viremia (VI) with peak levels $>50$ copies/PCR for CMV \& EBV and $>2500$ copies/ml for BKV viremia was analyzed.

${ }^{* *}$ The comparison between the two groups was performed by Fisher's exact test.

1st CMV viremia with $>30$ and $>50$ copies/PCR occurred significantly earlier after transplant in the DES group (mean months after transplant 3.7 versus $6.7[p=0.02]$ and 3.4 versus $7.1[p=0.01]$, resp.). Viral-PCR monitoring was performed every month during the 1st 3 months after transplant and every 3 months afterwards up to 12 months followed by every 6 months during the 2 nd transplant year. Shorter duration of CMV viremia and the trend of lower CMV DNA peak levels observed in DES patients could be due to earlier recognition and treatment in the DES group. No PTLD was seen in either group. There was no significant difference in the BKAN rate or the time to BKAN development in the two groups.

We next analyzed viral infection status separately by pretransplant recipient's viral serology status that largely affects posttransplant viral infection rate and its associated complication [52]. Since pretransplant CMV and EBV sero negativity were significantly higher in the non-DES group, this may have contributed to higher CMV and EBV viremia rates in non-DES patients. We divided DES and non-DES patients into 2 subgroups, CMV sero(+) or (-) and EBV sero(+) or (-). The CMV or EBV viremia status was compared among sero(+), sero(-) DES, sero(+), and sero(-) non-DES patients. The analysis for BKV infection was not performed since BKV serology results were not readily available.

Freedom from CMV or EBV viremia with $>30$ copies/ PCR in the 4 groups is shown in Figure 3, and the CMV or EBV viremia rates with 3 cutoff levels are shown in Tables 3 and 4, respectively. Overall, sero(-) non-DES patients showed least freedom from CMV and EBV viremia during the 1st 5 years after transplant (Figure 3, Tables 3 and 4). In the non-DES group, the CMV and EBV viremia rates were significantly higher in sero(-) versus sero(+) patients (44\% versus $33 \%[p=0.01], 35 \%$ versus $23 \%[p<0.001]$, and $35 \%$ versus $19 \%[p<0.001]$ for CMV viremia; $37 \%$ versus $32 \%[p=0.02], 27 \%$ versus $11 \%[p<0.001]$, and $23 \%$ versus $5 \%[p<0.001]$ for EBV viremia with $>5,>30$, and $>50$ copies/PCR, resp.) (Tables 3 and 4, Figure 3). In contrast, significant difference in $\mathrm{CMV}$ and $\mathrm{EBV}$ viremia rate between sero(-) versus (+) was not observed in the
DES group. When the results were compared among CMV sero(-) patients, the CMV viremia rate was lower in the DES group (22\% versus $44 \%[p=0.03$ ], $20 \%$ versus $35 \%$ $[p=0.09]$, and $19 \%$ versus $35 \%[p=0.05]$ for CMV viremia with $>5,>30$, and $>50$ copies/PCR, resp.), while the viremia rate was similar in sero(+) DES and non-DES patients (Table 3), suggesting that lower CMV viremia rates observed in DES patients resulted in part from lower CMV viremia in sero(-) DES patients. Among the CMV sero(+) patients, significantly shorter duration of CMV viremia with $>30$ and $>50$ copies/PCR was again observed in DES than non-DES patients (mean months 0.7 versus 1.1 [ $p=0.02$ ], 0.8 versus 1.2 $[p=0.03]$, resp.). This might be due in part to earlier onset of CMV viremia in DES than non-DES patients (mean months after transplant 3.5 versus $8.1,[p=0.02]$, 3.1 versus $9.2[p=$ 0.01], resp.). Among EBV sero(+) patients, the EBV viremia rate was significantly or near significantly lower in the DES group: $14 \%$ versus $32 \%$ [ $p<0.001]$, 2.8 versus $11 \%[p<0.01$ ], and 2.5 versus $5.4 \%$ [ $p=0.09]$ for viremia with $>5,>30$, and $>50$ copies/PCR, respectively (Table 4 ). Among EBV sero(-) patients, only 2 of $13(15 \%)$ DES patients had viremia with $>5$ copies/PCR and none showed viremia with $>50$ copies/PCR during the study period. In contrast, 11 of 33 (33\%) non-DES had viremia with $>5$ copies/PCR and 7 (21\%) showed viremia with $>50$ copies/PCR, suggesting EBV viremia also tended to be lower in sero(-) DES patients, although this difference was not statistically significant. These results suggest that lower EBV viremia rates observed in DES patients resulted from lower EBV viremia in sero(+) and to a lesser degree in sero(-) DES patients. Taken together, the standard protocol used for DES patients affects primarily CMV sero(-) patients to reduce CMV viremia as well as EBV sero(+) and to a lesser degree sero(-) patients to reduce EBV viremia rates. The treatment did not increase the BKV viremia and BKAN rate in DES patients.

ATG is widely used as an induction and rejection treatment agent in transplant patients, and use of a newer lymphocyte depleting agent, alemtuzumab, is also well established $[17,19]$. Use of these agents is essential due to their significant reduction of acute rejection, primarily cell-mediated, especially in high risk HS patients. Although the risk for 


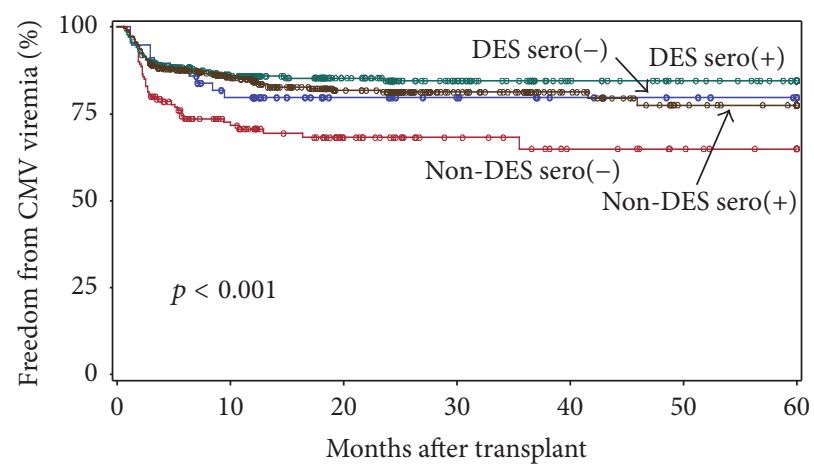

(a) CMV viremia with $>30$ copies/PCR

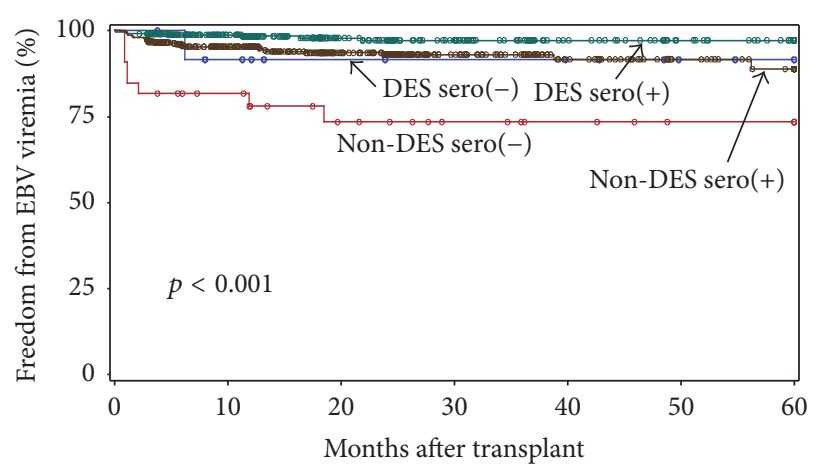

(b) EBV viremia with $>30$ copies/PCR

Figure 3: Freedom from CMV (a) or EBV (b) viremia with $>30$ copies/PCR in sero(+) (green) or sero(-) (blue) DES and sero(+) (brown) or sero(-) (red) non-DES patients during the 1st 5 years after transplant. The group differences were assessed by the log-rank test.

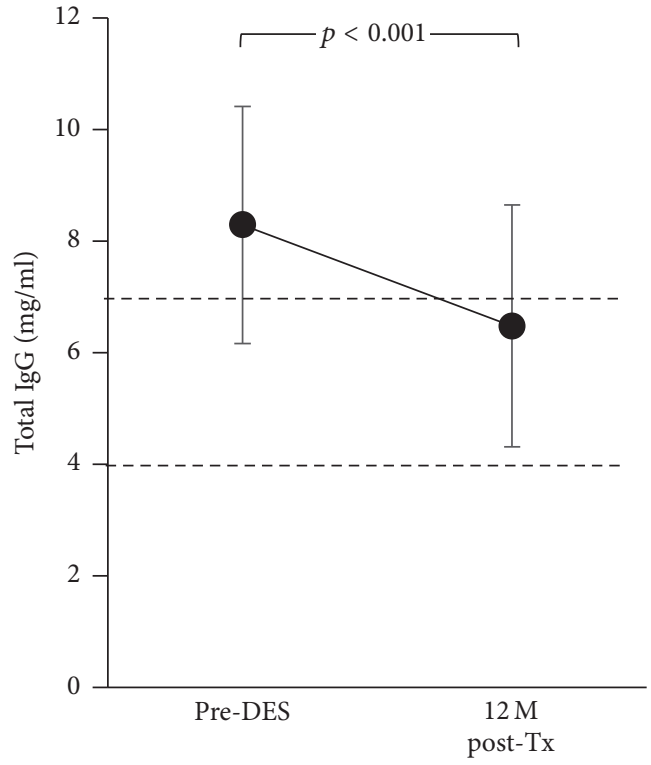

(a) Total IgG

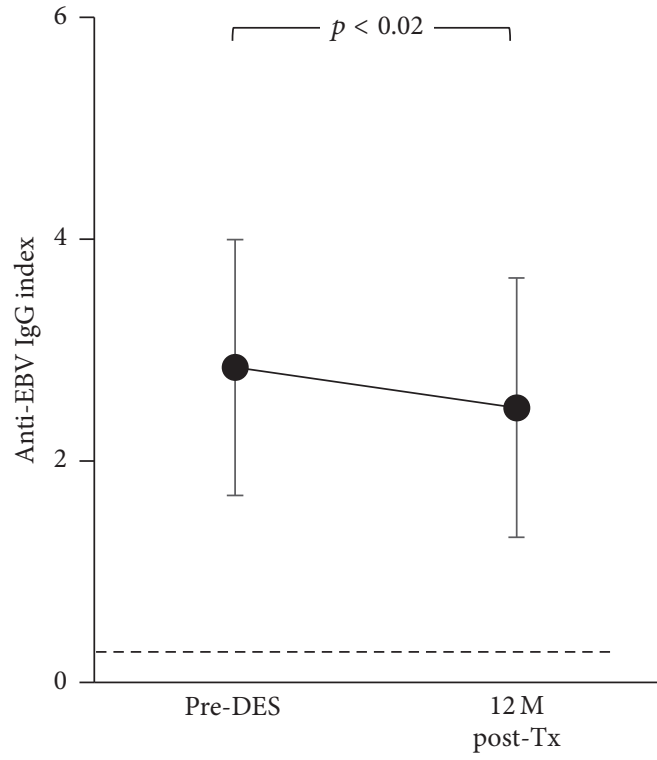

(b) Anti-EBV IgG

Figure 4: Total IgG (a) and anti-EBV IgG levels (b) before DES and at 12 months (M) after transplant (Tx) in 35 and 33 DES patients, respectively, who received DES with IVIg + rituximab followed by a kidney transplant with alemtuzumab induction. The results are expressed as mean and standard deviation. The dotted lines describe 7 and $4 \mathrm{mg} / \mathrm{ml}$ total IgG for the normal and severe hypogammaglobulinemia cutoff, respectively, in (a), and anti-EBV IgG index 0.25 for sero(+) cutoff level in (b).

viral infection is a concern due to severe and prolonged lymphocyte depletion, the viral infection risk reported in studies is inconsistent [17, 19, 22, 53-55]. This must be due to various conditions used in these studies such as type of transplantation, the type and dose of maintenance immunosuppressive drugs, application of rejection treatment drugs, type of viruses, viral serological status of recipient, and donor or viral prophylaxis [19]. Several studies showed similar results to ours. Hanaway et al. [17] reported no difference in $\mathrm{CMV}, \mathrm{EBV}$, and $\mathrm{BKV}$ infections between alemtuzumab versus ATG or anti-IL-2R induction during the first 3 years after transplant in high and low risk kidney transplant recipients with maintenance using tacrolimus, MMF, and 5-day steroid in a regimen of early steroid withdrawal. No significant difference in CMV and BKV infection in kidney transplant recipients who received alemtuzumab versus ATG or antiIL-2R induction $[22,56]$, and no difference in CMV, EBV, and HSV infection in HS patients with alemtuzumab versus ATG induction [57] was shown. In contrast to the above study results in HS patients [17,57], our study showed significantly lower CMV and EBV infection rates in HS (DES) with alemtuzumab compared to non-DES patients with ATG or anti-IL-2R induction. Our HS patients received DES before transplant, while those included in the previously mentioned 
studies did not. This difference might contribute to the observed lower incidence of CMV and EBV infection in our DES patients.

3.4. Possible Factors Contributing to Lower CMV and EBV Viremia Rates in DES Patients. Despite profound and prolonged $\mathrm{B}$ cell and $\mathrm{T}$ cell depletion from the standard protocol used for DES patients, pretransplant DES with IVIg + rituximab and posttransplant alemtuzumab induction, DES patients showed significantly lower CMV and EBV viremia rates compared to non-DES patients. In the further analysis performed separately by pretransplant CMV and EBV serological status, we found that the standard protocol used for DES patients reduced CMV viremia rate primarily in sero(-) and reduced EBV viremia rate in both sero(+) and sero(-) DES patients to a lesser degree. There are possible factors contributing to these observed beneficial effects of the standard protocol used for DES patients. Possible factors are summarized below.

3.4.1. Viral-Specific $T$ Cells. Viral infections are controlled primarily by antiviral T cells [58]. We have previously shown that CMV-specific CD8+ T cells (CMV-Tc) as analyzed by CFC were detected in most CMV sero $(+)$ healthy individuals as well as kidney transplant recipients, and clearance of CMV DNA was associated with detection of CMV-Tc in those patients [40]. Similar results have also been reported using CFC in solid organ transplant patients [59], ELISPOT in kidney transplant [60], QuantiFeron-CMV ${ }^{\circledR}$ [61], and Tetramerbased assays [62] in allogeneic stem cell transplantation. We also reported that CMV-Tc activity was detected by 2 and 4 months after transplant in 5 of 7 (71\%) and 7 of $7(100 \%)$ CMV sero(+) HS patients desensitized with IVIg + rituximab followed by a kidney transplant with alemtuzumab, respectively [39]. Our most recent study in a larger cohort of this patient population (30 patients) also showed similar results [37]: 70\% of CMV sero(+) patients showed negativity for CMV-Tc and CMV-specific CD4+ (CMV-Th) cells at 1 month after transplant (after alemtuzumab) due to T cell depletion. However, by 2 months after transplant, 75\% showed CMV-Tc and Th cell (+) and $95 \%$ did so by 3 months after transplant. These results suggest that a few viral-specific memory T cells that remained after alemtuzumab cell depletion are capable of responding to the virus, resulting in IFN $\gamma$ production and cytotoxic effector functions against infected cells in CMV sero(+) patients. Preservation of memory $\mathrm{T}$ cell function following aggressive depletion by alemtuzumab $[63,64]$ and low risk of virus infection in transplant recipients treated with alemtuzumab $[65,66]$ have also been reported by other investigators. In the above study [37], we have also shown that one CMV sero(-) patient who developed CMV viremia with $>1000$ copies/PCR at 2 months after transplant rapidly developed both $\mathrm{CMV}-\mathrm{Tc}$ and $\mathrm{Th}$, and the viremia was cleared within a month, demonstrating that even CMV sero(-) patients can develop de novo proliferating CMV-T cells after lymphocyte depletion with alemtuzumab. EBVspecific T cells as assessed by IFN $\gamma$ or TNF $\alpha$ positivity using the CFC assay were also detected in most EBV sero(+) normal individuals (Figure 5) and transplant recipients (data not shown). Clinical utility of EBV-specific T cell detection in lung, liver, and kidney transplant recipients using tetramer or ELISPOT assays have been reported by other investigators $[67,68]$. Taken together, availability of viral-specific T cells in sero(+) patients from early posttransplant and capability of efficiently developing viral-specific $\mathrm{T}$ cells in sero(-) patients, despite severe $\mathrm{T}$ cell depletion by alemtuzumab, must contribute at least in part to lower CMV and EBV viral infection in this patient population.

3.4.2. Antiviral Antibody. Antiviral antibody functions as one of the early defense mechanisms against viral infection in sero(+) individuals through neutralizing viruses and eliminating virus-infected cells [69-71]. It has been reported that low anti-CMV titer before transplant or at 1 month after transplant was associated with a higher risk of CMV disease in heart transplant recipients [72]. Elevated risk for CMV infection during the 1st year posttransplant was also reported in solid organ transplant recipients with severe hypogammaglobulinemia [73]. In addition, we and others have reported on the benefit of CMV immunoglobulin or IVIg use in the prevention and treatment of viral complications of transplantation including $\operatorname{CMV}[40,69,74]$, EBV/PTLD [75], parvovirus B19 [76], and BKV infections $[21,77]$. These study results demonstrate an important role of antiviral antibody in antiviral immunity in transplant recipients although neutralizing antibodies may not prevent subsequent rounds of infection and the cellular immune response eventually evolves to eradicate the infection [78]. Thus, long-term B cell depletion is always a concern in patients treated with rituximab followed by alemtuzumab induction. Our DES patients often received additional doses of rituximab posttransplant for treatment of ABMR, which may result in more prolonged $B$ cell depletion and possible reduction of antibodies including antiviral antibodies.

We have previously reported [39] that total IgG, IgM, and IgA levels significantly decreased 4-10 months after DES (equivalent to average 9.6 months after transplant) compared to the pre-DES levels in $14 \mathrm{HS}$ kidney transplant recipients with alemtuzumab induction. However, the reduction was only $15-20 \%$ and the reduced levels were still within the normal range in most patients. Minimal changes or moderate reductions (15-20\% reduction) in total Ig during 6-12 months after rituximab treatment have also been shown in patients with arthritis [79], those with relapsing-remitting multiple sclerosis [80], and those with active rheumatoid arthritis [81]. In addition, anti-CMV IgG levels in CMV sero(+) patients did not change from pre-DES levels up to 10 months after transplant. Based on these results, we suggested that antiCMV IgG might be produced primarily by CD20- long-lived plasma cells that are not affected by rituximab [82], while 15$20 \%$ of total IgG and IgM and IgA producing B cells might be CD20+ peripheral B cells and/or CD20- short-lived plasma cells [83].

In this study, we measured total IgG and anti-EBV IgG levels before DES and 12 months after transplant (15.7 \pm 2.9 months after DES) in 35 patients who received DES with IVIg + rituximab, followed by a kidney transplant with alemtuzumab induction. Total IgG levels significantly 


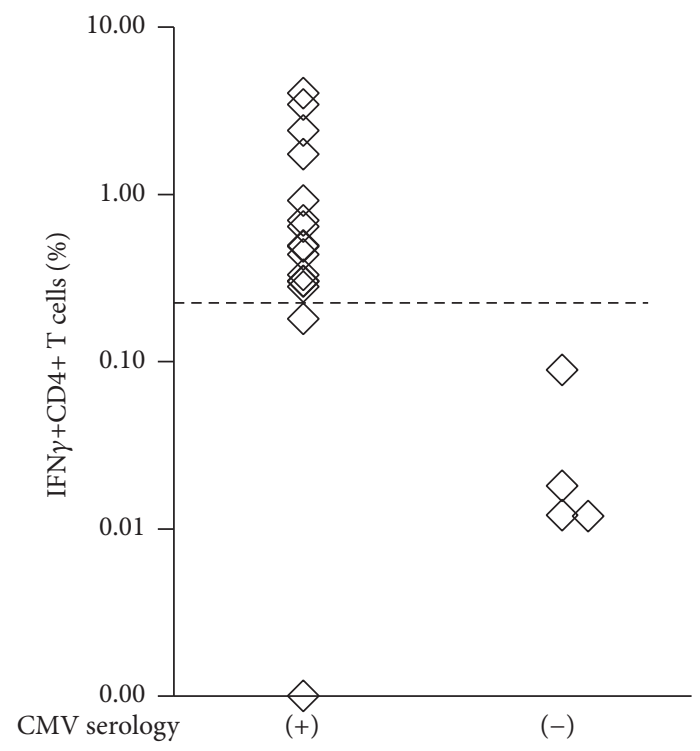

(a) CMV-specific CD4+ T cells

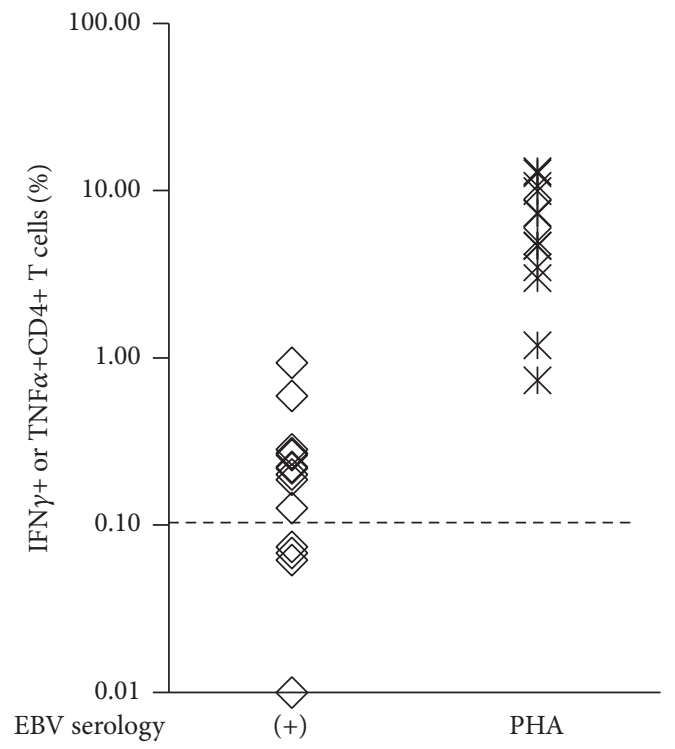

(c) EBV-specific CD4+ T cells

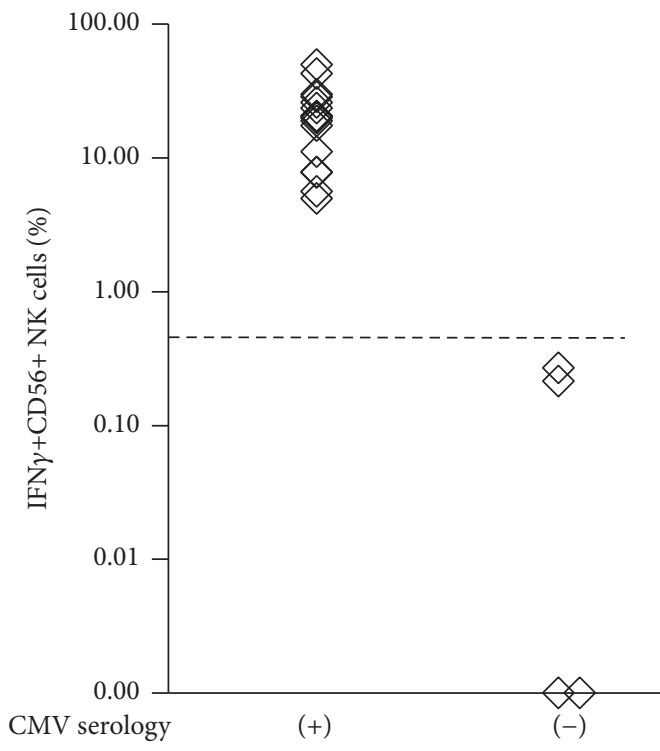

(b) CMV-specific CD56+ NK cells

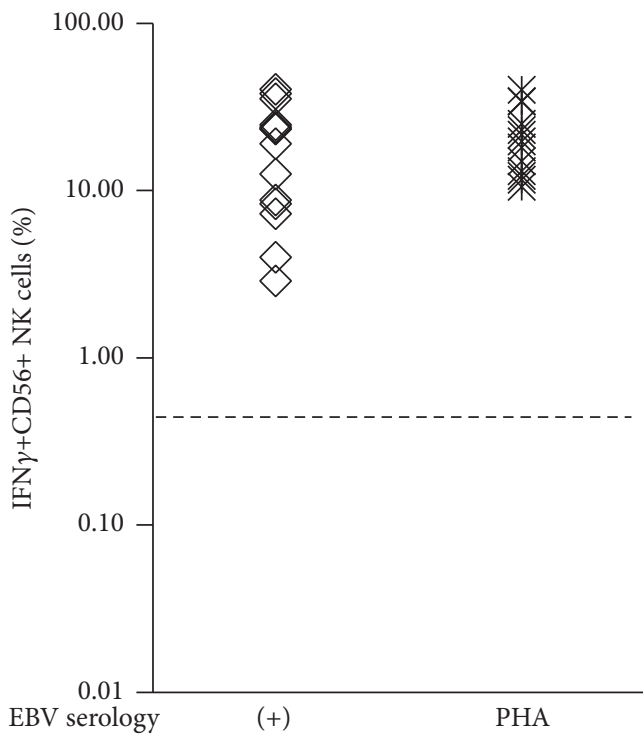

(d) EBV-specific CD56+ NK cells

Figure 5: The levels of CMV-specific CD4+ T cells (CMV-Th) (a) and CD56+ NK cells (CMV-NK) (b) in 16 CMV sero(+) and 4 sero(-) normal individuals and EBV-specific CD4+ T cells (EBV-Th) (c) and CD56+ NK cells (EBV-NK) (d) in 14 EBV sero(+) normal individuals as analyzed by CFC. Each symbol represents the result from one individual. The dotted line describes the positive cutoff level; $\geq 0.2 \%$ for CMV-Th, $\geq 0.1 \%$ for EBV-Th, and $\geq 0.5 \%$ for CMV- and EBV-NK. The PHA (+) control results were also shown in (c) and (d).

decreased at 12 months after transplant compared to preDES levels (22\% reduction) (Figure 4(a)), which is consistent with our previous results [39]. However, mean total $\operatorname{IgG}$ levels at 12 months after transplant was $6.5 \mathrm{mg} / \mathrm{ml}$ that is close to normal level, $>7 \mathrm{mg} / \mathrm{ml}$, and all patients except for two showed levels $>4 \mathrm{mg} / \mathrm{ml}$. Levels $<4 \mathrm{mg} / \mathrm{ml}$, considered severe hypogammaglobulinemia, are often associated with increased risk of viral and fungal infections and higher mortality $[73,74]$. Pre-DES levels in the two patients with posttransplant total $\operatorname{IgG}<4 \mathrm{mg} / \mathrm{ml}$ were 2.5 and $6.2 \mathrm{mg} / \mathrm{ml}$, already lower than normal levels. Florescu et al. reported based on a meta-analysis [73] that $45 \%$ of solid organ transplant recipients had hypogammaglobulinemia (total IgG $<7 \mathrm{mg} / \mathrm{ml}$ ) within the 1st year after transplant and $15 \%$ had severe hypogammaglobulinemia $(<4 \mathrm{mg} / \mathrm{ml})$. In the current study, $20 / 35$ patients (57\%) showed total $\mathrm{IgG}<7 \mathrm{mg} / \mathrm{ml}$ that was slightly higher than their report, but only $2 / 35$ (6\%) showed severe hypogammaglobulinemia requiring transient treatment with IVIg.

In contrast to posttransplant anti-CMV IgG levels observed in the previous study [39], anti-EBV IgG levels significantly decreased in EBV sero(+) patients at 12 months after transplant in this study (Figure 4(b)). However, the reduction was minimal, $11 \%$. Taken together, consistently 


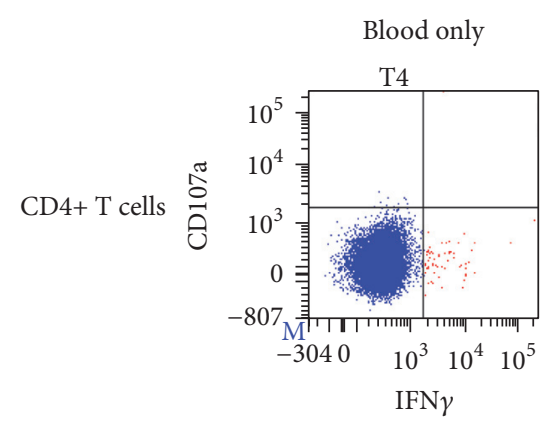

(a)

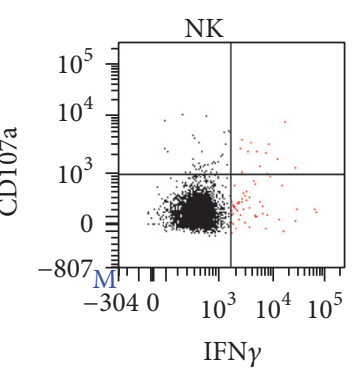

(e)

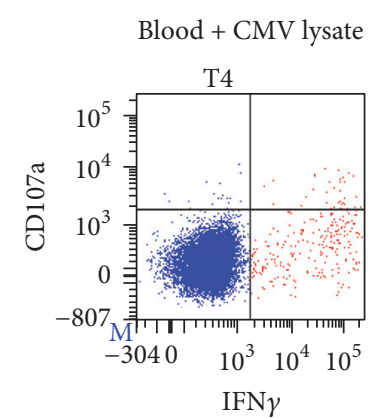

(b)

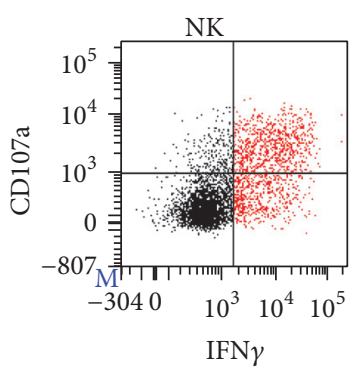

(f)

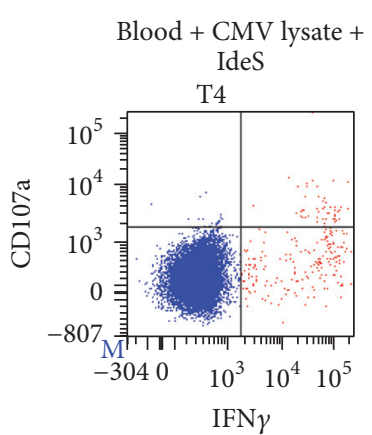

(c)

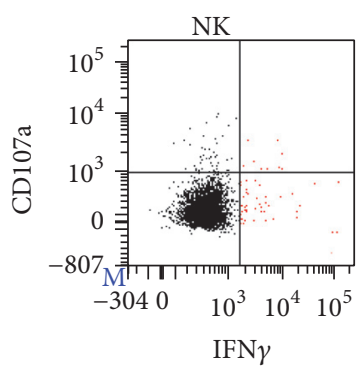

(g)

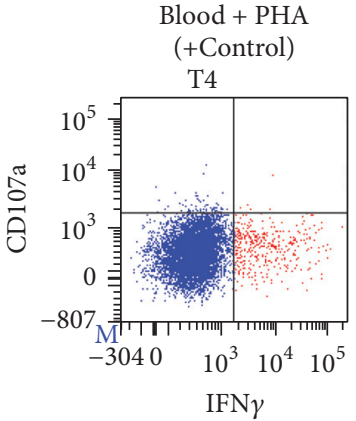

(d)

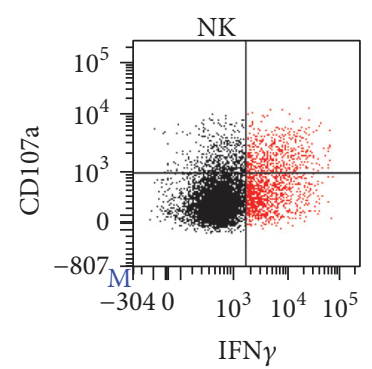

(h)

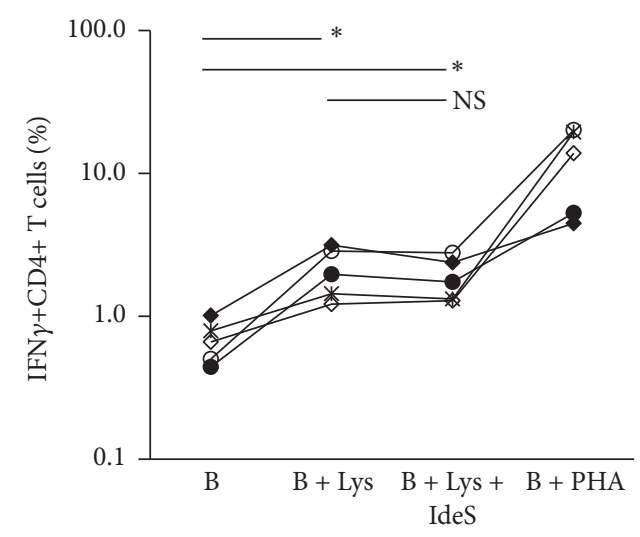

(i) CMV-specific CD4+ T cells

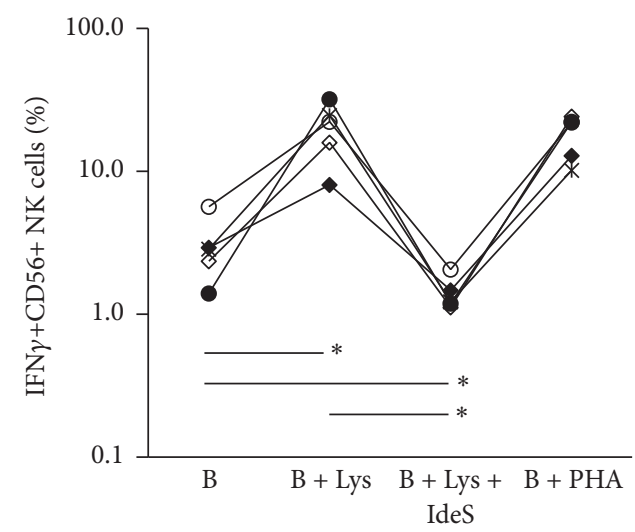

(k) CMV-specific CD56+ NK cells

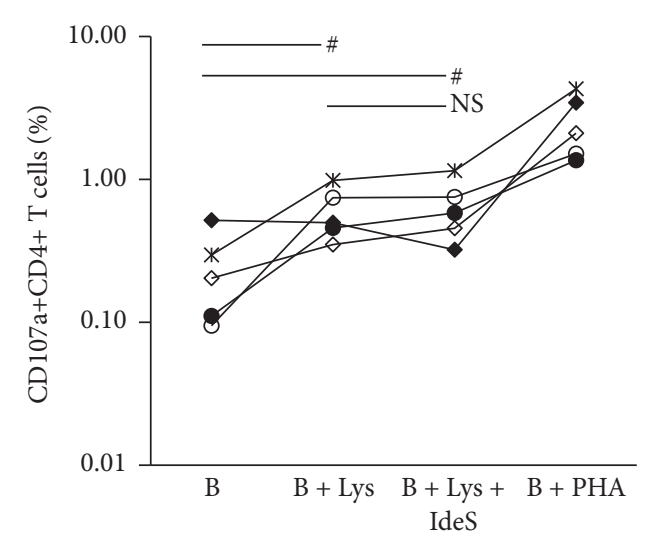

(j) CMV-specific CD4+ T cells

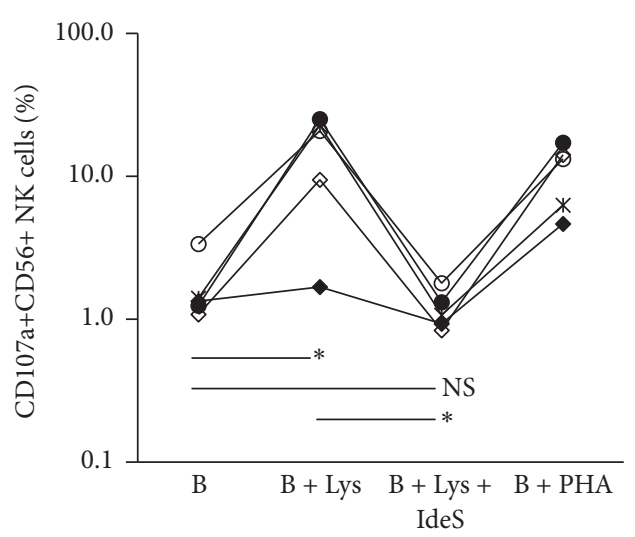

(1) CMV-specific CD56+ NK cells

FIGURE 6: Involvement of anti-CMV IgG in positive reactivity of CMV-Th and CMV-NK cells. Upper (a-h): a typical result of the CMVTh and CMV-NK assay performed with or without IdeS, IgG-degrading enzyme. Lower (i-1): the summary of 5 sets of experiment results using 5 different normal individuals. Each line with each symbol describes the result from one normal individual. B: blood; Lys: CMV lysate. ${ }^{*} p<0.05,{ }^{\#} p=0.05-0.1$, and NS: not significant $(p \geq 0.1)$ as assessed by paired $t$-test. 
available anti-CMV and anti-EBV IgG that are not affected by prolonged $\mathrm{B}$ cell depletion must contribute at least in part to lower CMV and EBV viral infection in sero(+) DES patients.

3.4.3. Antibody-Dependent Cell-Mediated Cytotoxicity (ADCC). $\mathrm{ADCC}$ is one of the major antiviral activities and mediated by Fc $\gamma$ RIIIa (CD16) bearing cells such as NK cells, monocytes, and a subset of CD8+ T cells through interaction of CD16 with Fc portion of antiviral IgG bound to the viral infected targets [70, 71, 84, 85]. Among the CD16 bearing cells, NK cells are primarily responsible for ADCC. As shown in Figure 1 and in previous studies [37, 39], CD56+/CD16+ NK cell numbers did not decrease as much as T cells after alemtuzumab induction in DES patients. In this study, 20$50 \%$ of pre-DES NK cell levels were already detected at 1 month after transplant and $>50 \%$ of pre-DES levels by 3 months (Figure $1(\mathrm{~d})$ ) in most patients. In addition, anti-CMV and anti-EBV IgG levels showed no or minimal changes after transplant (after alemtuzumab) in CMV and EBV sero(+) patients, respectively [39] (Figure 4). These results suggest that NK cells-anti-CMV or anti-EBV IgG-mediated ADCC may be another factor contributing to lower rate of CMV or EBV infection in sero(+) DES patients.

To address this possible ADCC activity in sero(+) patients, we measured NK cell response to CMV or EBV lysate (CMV- or EBV-NK) in vitro by assessing IFN $\gamma$ production and CD107a expression, degranulation marker [41, 86], using a CFC technique. We first measured the IFN $\gamma+$ cell\% in CD4+ $\mathrm{T}$ and CD56+ NK cells in response to CMV in 20 and EBV lysate in 14 normal individuals; 4 of 20 were CMV sero(-) and all 14 were EBV sero(+). Most CMV sero(+) individuals except for two showed CMV-Th $(+)$ $(\geq 0.2 \%)$, while all 4 sero(-) individuals were $(-)$ for CMVTh (Figure 5(a)). Similar responses were seen in all $16 \mathrm{CMV}$ sero $(+)$ individuals showing $(+)$ for CMV-NK $(\geq 0.5 \%)$, while all sero(-) showed CMV-NK(-) (Figure 5(b)). In the EBVTh and NK assay, 10 of 14 showed EBV-Th $(+)(\geq 0.1 \%)$ and the remaining 3 were $(-)$ (Figure $5(\mathrm{c})$ ), while all 14 showed $(+)$ for EBV-NK (Figure 5(d)). All PHA positive controls were $(+)$ for EBV-Th and NK (Figures 5(c) and 5(d)).

It is well accepted that CMV- or EBV-T cells are viralspecific memory $\mathrm{T}$ cells and their response to CMV or EBV peptides or lysate in vitro are mediated through $\mathrm{T}$ cell receptors $[40,59,67,68]$. NK cells express various receptors that are critical to their function and have traditionally been classified as important effectors of the innate immune system [87]. As characterization of NK cells has advanced, their crucial role in immunity has been reaffirmed and expanded [88, 89]. Recent studies suggest that NK cells have the capacity for immunological memory $[90,91]$. To determine if the NK cell activation in response to CMV lysate observed in this study was mediated by direct interaction of NK cell receptors with CMV antigens on the lysate or antigen presenting cells, or an indirect interaction of NK cells with CMV antigens via CD16 and anti-CMV antibody interaction, similar experiments were performed using IdeS, an IgG-degrading enzyme [92], which enzymatically digest intact IgG into $\mathrm{F}\left(\mathrm{ab}^{\prime}\right)_{2}$ and $\mathrm{Fc}$ fragments, in $5 \mathrm{CMV}$ sero(+) normal individuals, with subsequent analysis of the IFN $\gamma+$ cell\% and CD107a+ cell\% in CD4+ T and CD56+ NK cells. IFN $\gamma+$ and CD107a + cell\% in CD4+ T cells and CD56+ NK cells were elevated when blood was stimulated with $\mathrm{CMV}$ lysate (Figures 6(b), 6(f), and 6(i)-6(l)). The elevated IFN $\gamma+$ and $\mathrm{CD} 107 \mathrm{a}+$ cell\% in $\mathrm{CD} 4+\mathrm{T}$ cells remained when blood pretreated with IdeS was used for the assay (Figures 6(c), 6(i), and 6(j)). In contrast, the elevated IFN $\gamma+$ and CD107a+ cell\% in CD56+ NK cells was completely abrogated when blood was pretreated with IdeS (Figures 6(g), 6(k), and 6(l)). These results suggest that $\mathrm{CD} 4+\mathrm{T}$ cell activation in response to CMV lysate is anti-CMV antibody-independent and is memory $\mathrm{T}$ cell response specific to $\mathrm{CMV}$ antigens via $\mathrm{T}$ cell receptor as expected, while CD56+ NK cell activation in response to CMV lysate is anti-CMV antibody-dependent via CD16 and the involvement of other NK cell receptors is unlikely as NK cell activation was similar to background level after IdeS treatment. To determine if the complete inhibition of IFN $\gamma$ production and CD107a expression by IdeS in NK cells was due to an interaction of IdeS with NK cells, blood stimulated with PHA (positive control) was incubated with or without IdeS in the CMV-T and NK assay. As shown in Figure 7, the elevated IFN $\gamma+$ and CD107a+ cell\% in NK cells stimulated with PHA remained elevated even when blood was treated with IdeS (Figures 7(e), 7(f), 7(i), and 7(j)), suggesting that IdeS has no direct suppressive effect on NK cells. The same is true for the elevated IFN $\gamma+$ cell\% in CD4+ T cells (Figures 7(b), 7(c), and 7(g)), while CD107a expression in PHA-stimulated CD4+ cells was minimal (Figures 7(b), 7(c), and $7(\mathrm{~h})$ ). Taken together, these results demonstrate that it is likely that ADCC plays an important role in prevention and reduction of CMV and EBV infection in sero(+) DES patients, especially during the first 1-2 months after transplant when less antiviral $T$ cells are available in many patients due to alemtuzumab induction. ADCC-mediated antiviral activity is also likely to take a part of controlling viral infection in sero(-) patients who are treated with CMV-Ig or IVIg as it has been reported that elimination of CMV or EBV-infected cells by CMV-Ig or IVIg was enhanced by addition of NK cells via ADCC [85].

Recent studies showing the important role of antibodymediated NK cell activity beyond a traditional ADCC mechanism in controlling CMV infection are of interest [9395]. Elevated number and activity of NK cells during CMV infection in transplant recipients were previously reported [94]. Recently, NKG2C ${ }^{\text {hi }} \mathrm{CD} 57^{\text {hi }} \mathrm{NK}$ cells have been identified to be expanded exclusively at CMV infection $[93,96,97]$ and its effector function is enhanced only in the presence of antiCMV antibodies [95]. IFN $\gamma+$ and CD107a + NK cells activated via antibody in response to CMV lysate as detected in the CMV-NK assay of this study might be this particular NK cell subset.

3.4.4. Lymphocyte Depletion. Contrary to the widely held concept that lymphocyte depletion increases risk for viral infections, several studies including a meta-analysis showed a similar viral infection rate among patients treated with alemtuzumab, ATG, and anti-IL-2R induction [17, 22, 56]. Our DES patients included in this study received an additional lymphocyte depleting agent, rituximab, for pretransplant 


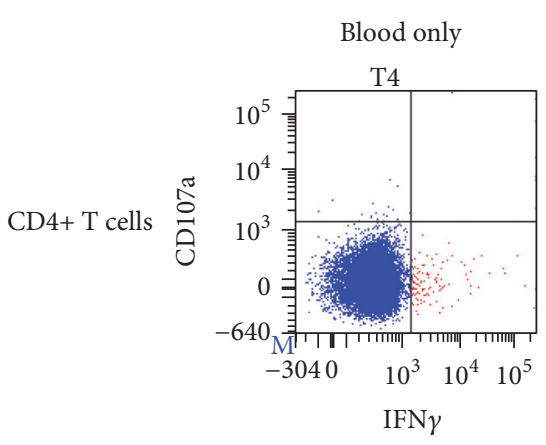

(a)

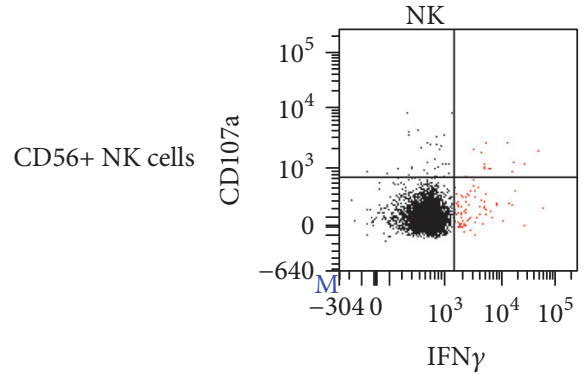

(d)

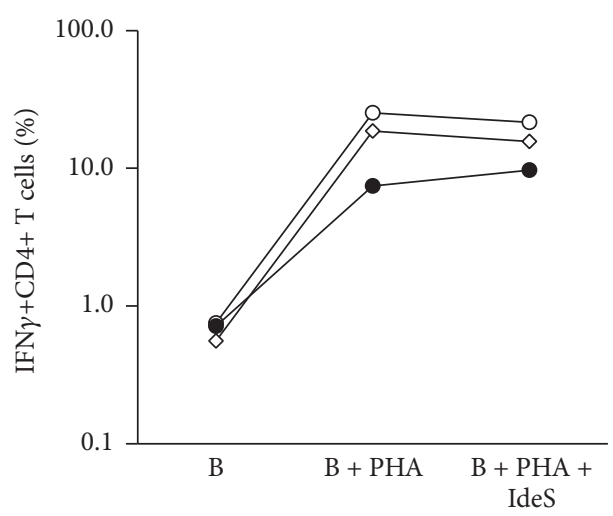

(g) PHA-stimulated CD4+ T cells

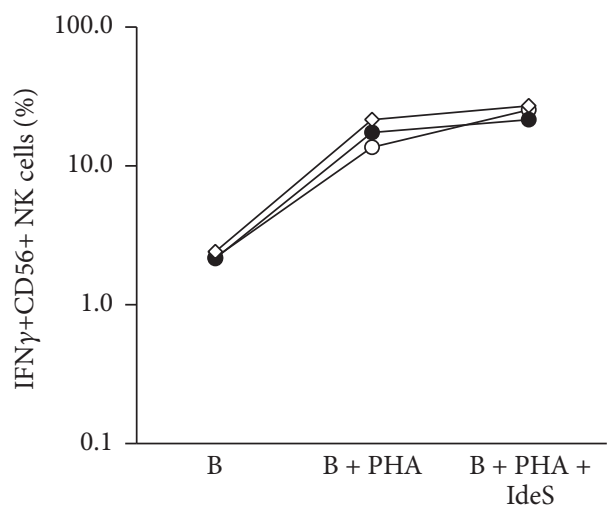

(i) PHA-stimulated CD56+ NK cells

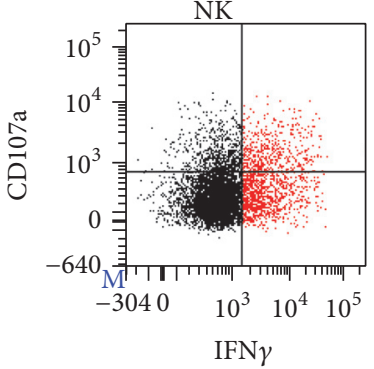

(e)

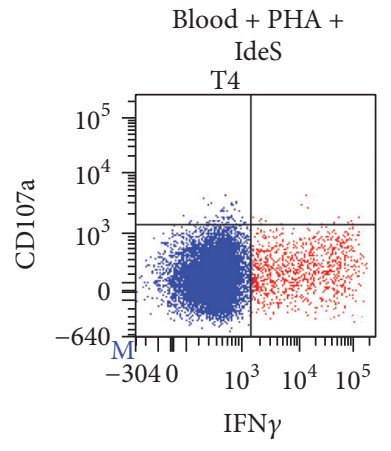

(c)

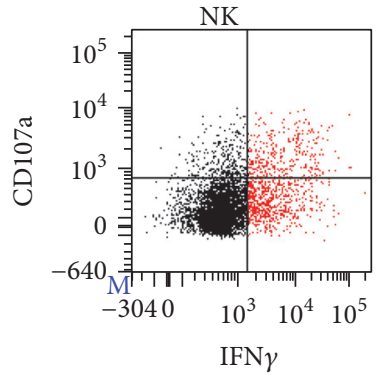

(f)

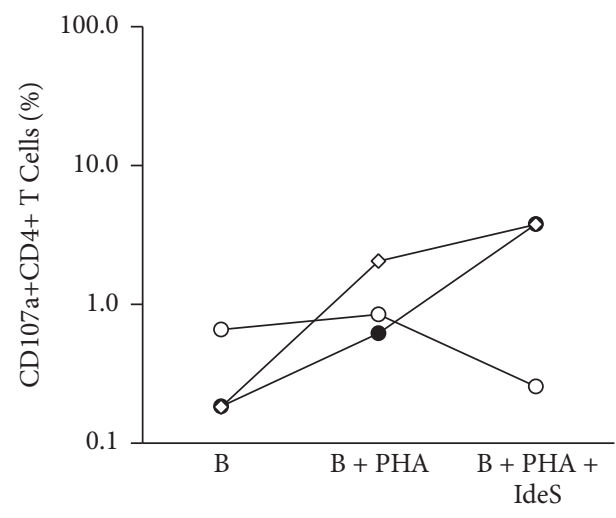

(h) PHA-stimulated CD4+ T cells

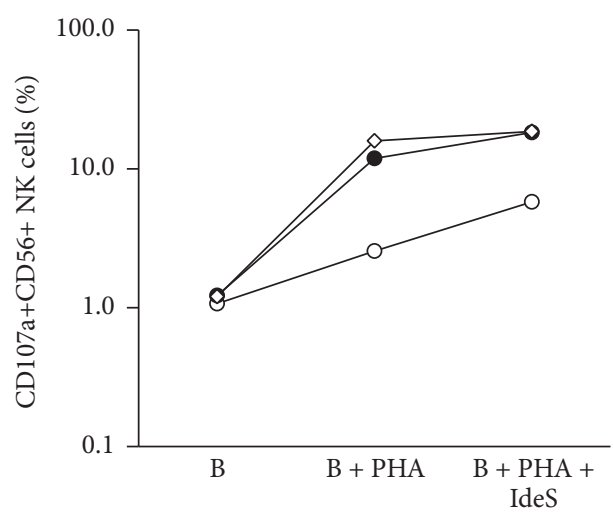

(j) PHA-stimulated CD56+ NK cells

Figure 7: The effect of IdeS on CD4+ T cell and CD56+ NK cell activation in response to PHA. Upper (a-f): a typical result of CD4+ T cell and CD56+ NK cell response to PHA (positive control) with or without IdeS in the CMV-Th and CMV-NK assay. Lower (g-j): the summary of 3 sets of experiment results using 3 different normal individuals. Each line with each symbol describes the result from one normal individual. B: blood. 
DES and treatment of ABMR in some patients, and these patients showed even lower CMV and EBV infection rate compared to non-DES patients (Tables 2, 3, and 4 and Figures $2,3)$, suggesting that lymphocyte depletion itself might be one of possible factors for the lower viral infection rate in this patient population.

EBV enters B cells via the $\mathrm{C} 3 \mathrm{~d}$ complement receptor CD21 and establishes its latency on B cells [98]. As EBV is detected in a wide range of $B$ cells, from resting $B$ cells through blast cells to fully differentiated plasma cells, B cells are considered the primary reservoir for EBV [99]. Our study showed that the EBV viremia rates were significantly lower in EBV sero $(+)$ DES and also tended to be lower in EBV sero(-) DES patients (Table 4). Elimination of EBV reservoirs, B cells, by rituximab and alemtuzumab used for DES and induction therapy may reduce the reactivation of latent EBV and/or primary infection in this patient population. In fact, only 2/13 (15\%) EBV sero(-) DES patients developed EBV viremia, one with $<50$ and another with $<30$ copies/PCR, and none had EBV viremia with $>50$ copies/PCR, which was in contrast to $7 / 33$ $(21 \%)$ in EBV sero(-) non-DES patients, although this was not statistically significant $(p=0.08$, Table 4$)$. Earlier studies showed no EBV reactivation in patients previously treated with rituximab $[100,101]$ and an association of a lower risk for PTLD by treatment with T cell and B cell depleting agent, alemtuzumab, compared to an agent depleting only T cells, ATG, in hematopoietic cell transplantation [29]. Recently, Schachtner and Reinke [102] reported that a single dose of rituximab 4 weeks prior to transplant significantly reduced posttransplant EBV viremia in EBV sero(-) kidney transplant recipients who received EBV sero(+) kidney, compared to those without rituximab treatment, and no patient developed PTLD. These patients received induction with either antiIL-2R or ATG, and maintenance with calcineurin inhibitor + MMF + steroid. Thus, we think that the low incidence of EBV viremia observed in DES patients of our study is likely due to rituximab used for DES, although a subsequent use of alemtuzumab induction might further increase this beneficial effect in DES patients.

After primary CMV infection, the virus can persist in a latent form in a variety of tissues, primarily in monocytederived macrophages and dendritic cells $[29,103,104]$. The CMV viremia rate was reduced in DES compared to non-DES patients, primarily in CMV sero(-) DES patients. (Table 3). Monocytes and myeloid dendritic cells express CD52 at high levels, but these are less susceptible to alemtuzumabmediated complement-dependent cell cytotoxicity due to high levels of complement inhibitory proteins expressed on these cells [47]. Thus, unlike B cells for EBV, it is unlikely that the elimination of CMV reservoir is a major reason for lower CMV viremia rate observed in DES patients.

BKV establishes latency in the uroepithelium after a primary infection, $[6,105]$. Reactivation and replication occur in immunocompromised patients such as transplant recipients, resulting in viruria. When replication is aggressive, BKV viremia emerges due to injured renal epithelial cells. Currently, it is well accepted that the primary reservoir for BKV is renal epithelial cells, and suggested that the source of BKV in plasma is derived from BKV replication in the allograft of kidney transplant recipients [105]. Thus, alemtuzumab and rituximab have no ability to reduce or prevent BKV infection through elimination of BKV reservoir.

3.4.5. Antiviral Prophylaxis. Antiviral prophylaxis or preemptive antiviral therapy is essential for prevention of viral infections and associated complications in transplant recipients [106]. Both strategies are acceptable, but differences are noted [107-110]. Currently, ganciclovir and valganciclovir are commonly used as first-line antiviral prophylaxis and are most effective in preventing CMV infection and disease, although inhibition of other herpes viruses (herpes simplex virus types 1 and 2 [HSV-1, HSV-2], EBV, varicella-zoster virus [VZV], and human herpes virus 6 [HHV-6]) is noted $[106,110]$. Acyclovir is also used as antiprophylaxis agent but does not have significant efficacy against CMV compared to HSV-1 and HSV-2, VZV, and EBV [108, 110].

All patients included in this study received antiviral prophylaxis with ganciclovir while inpatient and then valganciclovir or acyclovir posttransplant depending on a risk for CMV infection based on donor and recipient CMV serologies. Briefly, for transplants with lymphocyte depletion induction and those with CMV R-/D+ regardless of induction type, valganciclovir was given. For those with anti-IL-2R induction and CMV R+/D+, R+/D-, or R-/D-, acyclovir was given. In this study, we showed that CMV and EBV viremia rate in DES patients were significantly lower than non-DES patients. Most DES patients (86\%) received ganciclovir since they received lymphocyte depletion induction, while $51 \%$ of the non-DES patients received acyclovir due to anti-IL-2R induction and CMV sero-status. This difference in antiviral prophylaxis may be a reason for differences in viremia rates in the DES versus non-DES groups. To address this question, we compared the CMV and EBV viremia rates in non-DES patients with valganciclovir versus acyclovir. Since viral serostatus affects the viremia rate, only CMV or EBV sero(+) nonDES patients were included in this analysis. Among CMV sero(+) non-DES patients, 176 received valganciclovir and 175 received acyclovir (Table 5). No significant difference in CMV viremia with $>30$ copies/PCR was found in the two groups. Among EBV sero(+) non-DES patients, even those with valganciclovir showed higher EBV viremia rates compared to those with acyclovir (22 of 200 [11\%] versus $6 / 215[2.8 \%], p<0.001)$. These results indicate that higher CMV and EBV viremia rates observed in non-DES versus DES patients are unlikely due to acyclovir given to more non-DES patients. Since the most common induction agent used for DES patients was alemtuzumab and most non-DES patients received ATG, we further analyzed the viremia rate in sero(+) non-DES patients with valganciclovir who received alemtuzumab versus ATG. No significant difference in the CMV or EBV viremia rate was found (Table 5), suggesting that the difference in lymphocyte depleting agents is unlikely the reason for higher CMV and EBV viremia rates in nonDES patients in our patient population. It should be noted that non-DES patients who received alemtuzumab showed less EBV viremia rate compared to those with ATG (5\% versus $12 \%)$ as mentioned in the previous section, but this was not statistically significant. 
3.4.6. IVIg. IVIg derived from pooled human plasma from thousands of donors and originally used for the treatment of primary immunodeficiency disorders has also been used for the treatment of autoimmune and inflammatory disorders for nearly 30 years $[74,111,112]$ and is currently recognized as a potent immunomodulatory agent. It affects innate and adaptive immune systems, and its effect on most components of immune system including antibodies, complements, cytokines, most immune cells and their receptors, and the interaction of these components have been reported [74, $111,112]$. Precise mechanisms of immune modulation are still not well known although various possible mechanisms have been proposed depending on diseases or its clinical application. We have been using IVIg for the DES therapy as an immunomodulatory agent against allosensitization as previously reported [74, 113-116]. Antiviral properties found in IVIg as discussed at earlier section became an additional benefit for our DES patients. The low CMV and EBV viremia rate observed in DES compared to non-DES patients might be due in part to this IVIg effect.

3.5. Impact of Viral Infection on Allograft Rejection. We next investigated the impact of viral infection on allograft rejection. Of 372 DES and 538 non-DES patients, the rejection information was available in 363 DES and 497 nonDES patients during this study period. Freedom from total allograft rejection, $\mathrm{ABMR}$, and CMR in DES versus nonDES patients is shown in Figure 8. The DES group showed less freedom from overall allograft rejection $(p=0.08$, Figure 8(a)) during the 1st 5 years after transplant, but this was not statistically significant. When the analysis was performed separately by ABMR and CMR, freedom from ABMR in the DES group was significantly less than non-DES group $(p<$ 0.001 , Figure $8(\mathrm{~b}))$, which is common and a major obstacle in HS patients [12-15], while rates of CMR were similar in the two groups $(p=0.27$, Figure $8(\mathrm{c}))$. This demonstrated that the trend of less freedom from overall rejection observed in the DES was due to significantly less freedom from ABMR in the DES group. The number of patients who had overall allograft rejection (19\% versus 14\%, resp.), ABMR (12\% versus $2.2 \%)$, or CMR (11\% versus $14 \%$ ) during this study period in the DES and non-DES groups is also shown in Table 6.

To assess the impact of viral infection on induction of allograft rejection, we next analyzed the rejection rate within 6 months after onset of viral infection. Of 363 DES and 497 non-DES patients, 80 (22\%) and 138 (28\%) developed at least one CMV with $>50$, EBV with $>50$ copies/PCR, or BKV viremia with $>2500$ copies/ml during this study period (Table 6). Of these, $19 \%$ in the DES and $12 \%$ in the non-DES groups developed either ABMR or CMR within 6 months after viral infection, which was similar to the overall rejection rate in the whole DES and non-DES groups as shown above (19\% versus $14 \%)$. In addition, the AMR rate within 6 months after infection in the DES and non-DES groups $(10 \%$ and $2.2 \%$, resp.) is again similar to that in the whole DES and non-DES groups (12\% versus $2.2 \%$ ), and the same is true for the CMR rate after infection (14\% versus $11 \%)$. These results suggest that the impact of viral infection on induction of allograft rejection occurring within 6 months after infection is minimal in our patients, both DES and non-DES patients.

The increased risk of viral infections and their complications associated with antirejection therapy is well documented $[28,117]$. On the other hand, acute and chronic allograft injuries and rejections caused directly and indirectly by viral infections have also been suggested, but not conclusive $[28,29]$. In kidney transplant, CMV infection is known to mediate allograft injury and rejection likely through systemic inflammation, cytokines, and $\mathrm{T}$ cell activation induced by CMV $[28,117,118]$. However this trend has been dramatically reduced after application of anti-CMV prophylaxis [28, 107, 119]. All our patients, DES and non-DES, received antiviral prophylaxis for 6 months after transplant, which may minimize the impact of CMV infection on induction of allograft rejection.

3.6. Allograft and Patient Survival in DES and Non-DES Patients. We finally compared allograft and patient survival in DES versus non-DES patients included in this study (Figure 9). There was no significant difference in both allograft and patient survival in the two groups, which was previously reported in our other studies [14, 15, 26, 27]. The estimated graft (death-censored) and patient survival at 2 years after transplant were $93.4 \%$ and $95.6 \%$ in the DES and $96.1 \%$ and $94.9 \%$ in the non-DES groups, respectively.

\section{Conclusions}

Desensitized HS patients are at lower risk for CMV and EBV infections and have a similar risk for BKV infection and BKAN posttransplant. This trend was observed primarily in CMV sero(-) for CMV infection and in EBV sero(+) and sero(-) patients to a lesser degree for EBV infection. No patient developed PTLD in either group. Factors likely responsible for the lower risks for CMV and EBV infections in DES patients include (1) viral-specific memory $\mathrm{T}$ cells remaining after lymphocyte depletion with alemtuzumab are capable of efficiently proliferating to clear virus in sero(+) patients. In addition, sero(-) patients are capable of efficiently developing viral-specific $\mathrm{T}$ cells even after $\mathrm{T}$ cell and $\mathrm{B}$ cell depletion; (2) high levels of NK cells remaining after alemtuzumab and consistently available antiviral IgG after $\mathrm{T}$ cell and $\mathrm{B}$ cell depletion contribute to clearance of CMV and EBV through ADCC in sero(+) patients; (3) elimination of $B$ cells (EBV reservoirs) by rituximab and alemtuzumab, and to a lesser degree, monocytes (CMV reservoir) by alemtuzumab, may reduce or prevent the reactivation of latent infection and/or primary infection; (4) the use of IVIg which contains potent antiviral IgGs that likely have a beneficial effect in preventing or modulating viral infections. We have recently reported that $\mathrm{B}$ cell and $\mathrm{T}$ cell depletion is unlikely to increase a risk for polyomavirus JC (JCV) and progressive multifocal leukoencephalopathy (PML) in DES patients [24]. Allograft and patient survival were similar in both groups. Taken together, we conclude that the IVIg + rituximab DES combined with alemtuzumab induction with triple immunosuppression maintenance does not increase risk for $\mathrm{CMV}, \mathrm{EBV}, \mathrm{BKV}$, and $\mathrm{JCV}$ infections and their 


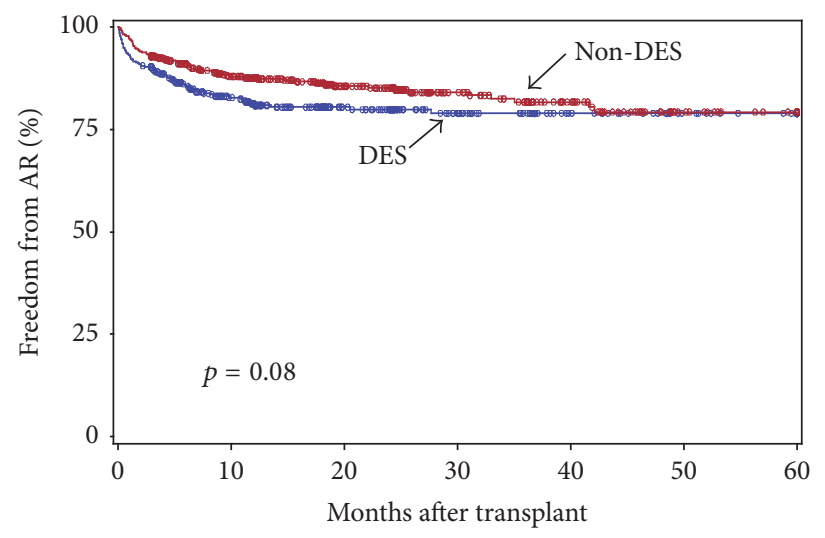

(a) Allograft rejection (ABMR or CMR)

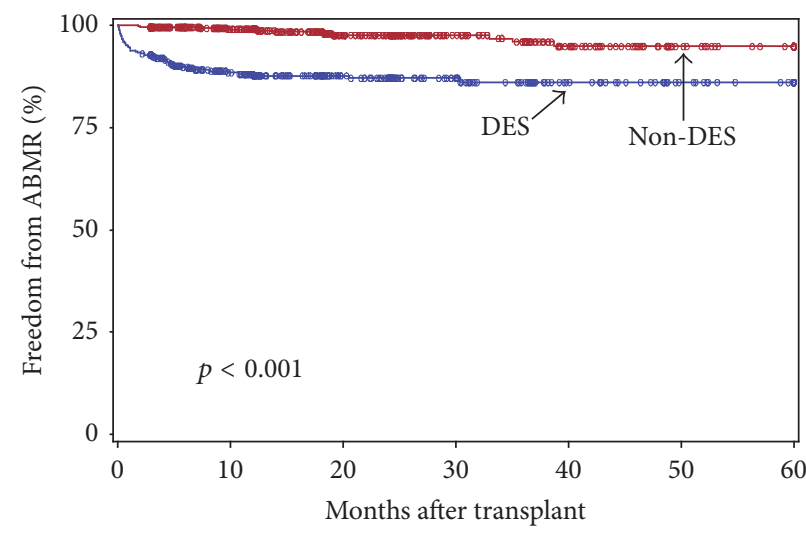

(b) ABMR

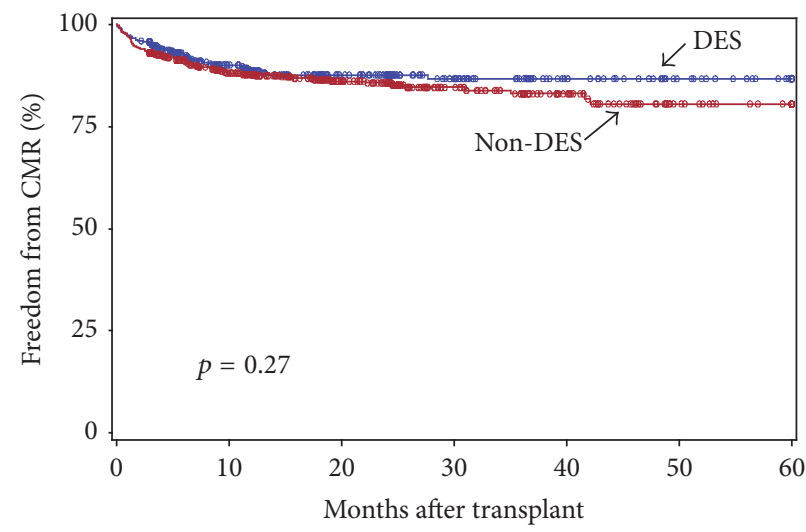

(c) CMR

FIGURE 8: Freedom from overall allograft rejection (a), ABMR (b), and CMR (c) in DES (blue) versus non-DES (red) patients during the 1st 5 years after transplant. The group differences were assessed by the log-rank test.

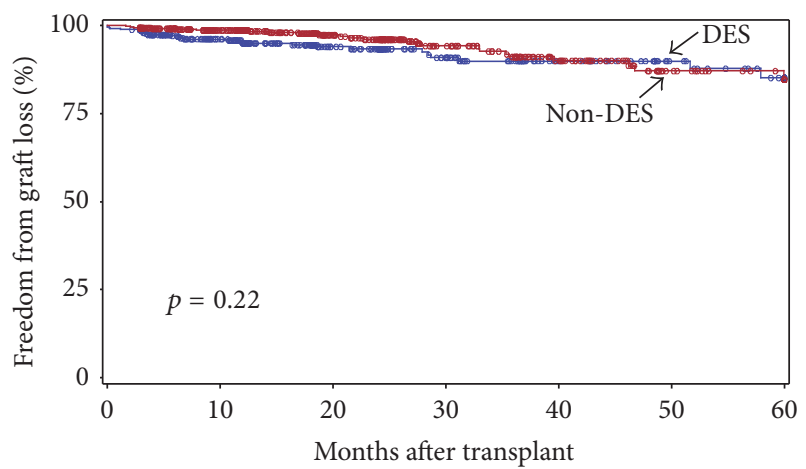

(a) Graft loss (death-censored)

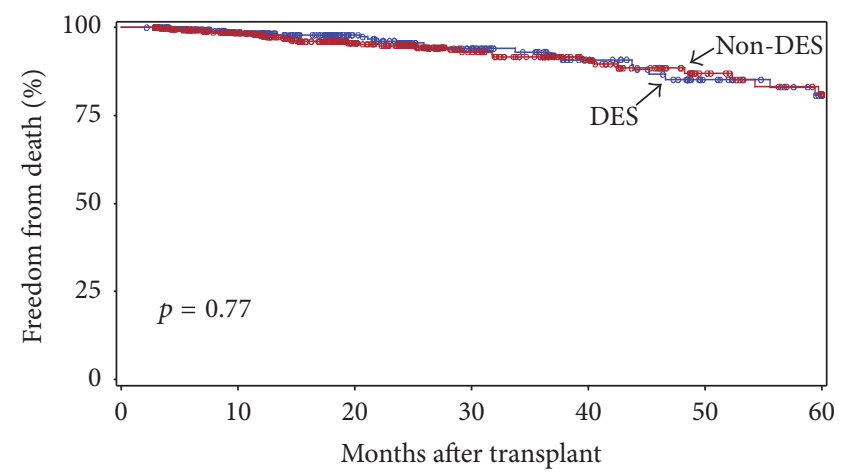

(b) Patient survival

FIGURE 9: Freedom from allograft loss (a) and patient death (b) in DES (blue) versus non-DES (red) patients during the 1st 5 years after transplant. The group differences were assessed by the log-rank test.

associated complications including PTLD, BKAN, and PML in HS kidney transplant patients under antiviral surveillance with antiviral prophylaxis for 6 months after transplant and close monitoring viral infection by PCR for early detection and early intervention.

\section{Competing Interests}

Stanley C. Jordan has research grants from Genentech Inc. and owns a patent (US Patent 6,171585B1): "IVIg Immunosuppression for HLA-Sensitized Transplant Recipients," 2001. 
The remaining authors declare that there is no conflict of interests regarding the publication of this paper.

\section{Authors' Contributions}

Mieko Toyoda participated in the research design, performance of the research, data analysis, data interpretation, and writing the paper. Bong-Ha Shin participated in the research design, performance of the research, and data analysis. Shili Ge participated in the research design, performance of the research, data analysis, data interpretation, and writing the paper. James Mirocha participated in the data analysis. David Thomas participated in the performance of the research, data analysis, and data interpretation. Maggie Chu, Edgar Rodriguez, Christine Chao, Anna Petrosyan, Odette A. Galera, Ashley Vo, Jua Choi, and Alice Peng participated in the performance of the research. Joseph Kahwaji participated in the performance of the research and data analysis. Stanley C. Jordan participated in the research design and writing the paper.

\section{References}

[1] G. Dotti, R. Fiocchi, T. Motta et al., "Lymphomas occurring late after solid-organ transplantation: influence of treatment on the clinical outcome," Transplantation, vol. 74, no. 8, pp. 1095-1102, 2002.

[2] M. T. Grattan, C. E. Moreno Cabral, V. A. Starnes, P. E. Oyer, E. B. Stinson, and N. E. Shumway, "Cytomegalovirus infection is associated with cardiac allograft rejection and atherosclerosis," The Journal of the American Medical Association, vol. 261, no. 24, pp. 3561-3566, 1989.

[3] H. Campe, G. Jaeger, C. Abou-Airam et al., "Serial detection of Epstein-Barr virus DNA in sera and peripheral blood leukocyte samples of pediatric renal allograft recipients with persistent mononucleosis-like symptoms defines patients at risk to develop post-transplant lymphoproliferative disease," Pediatric Transplantation, vol. 7, no. 1, pp. 46-52, 2003.

[4] J. A. Fishman and R. H. Rubin, "Infection in organ-transplant recipients," The New England Journal of Medicine, vol. 338, no. 24, pp. 1741-1751, 1998.

[5] M. Toyoda, J. B. Carlos, O. A. Galera et al., "Correlation of cytomegalovirus DNA levels with response to antiviral therapy in cardiac and renal allograft recipients," Transplantation, vol. 63, no. 7, pp. 957-963, 1997.

[6] H. H. Hirsch, "Polyomavirus BK nephropathy: a (re-)emerging complication in renal transplantation," American Journal of Transplantation, vol. 2, no. 1, pp. 25-30, 2002.

[7] P. S. Randhawa and A. J. Demetris, "Nephropathy due to polyomavirus type BK," The New England Journal of Medicine, vol. 342, no. 18, pp. 1361-1363, 2000.

[8] S. V. McDiarmid, S. Jordan, G. S. Lee et al., "Prevention and preemptive therapy of posttransplant lymphoproliferative disease in pediatric liver recipients," Transplantation, vol. 66, no. 12, pp. 1604-1611, 1998.

[9] L. M. Demeter, "JC, BK, and other polyomaviruses; progressive multifocal leukoencephalopathy," in Principles and Practice of Infectious Diseases, G. L. Mandell, J. E. Bennet, and R. Dolin, Eds., Churchill Livingstone, New York, NY, USA, 5th edition, 2005.
[10] F. K. Baksh, S. D. Finkelstein, P. A. Swalsky, G. L. Stoner, C. F. Ryschkewitsch, and P. Randhawa, "Molecular genotyping of BK and JC viruses in human polyomavirus-associated interstitial nephritis after renal transplantation," American Journal of Kidney Diseases, vol. 38, no. 2, pp. 354-365, 2001.

[11] S. Rosen, W. Harmon, A. M. Krensky et al., "Tubulo-interstitial nephritis associated with polyomavirus (BK type) infection," The New England Journal of Medicine, vol. 308, no. 20, pp. 11921196, 1983.

[12] J. Kahwaji, J. Kahwaji, C. Tong, and S. C. Jordan, "Rituximab: an emerging therapeutic agent for kidney transplantation," Transplant Research and Risk Management, vol. 1, pp. 15-29, 2009.

[13] A. Loupy and S. C. Jordan, "Transplantation: donor-specific HLA antibodies and renal allograft failure," Nature Reviews Nephrology, vol. 9, no. 3, pp. 130-131, 2013.

[14] A. A. Vo, J. Choi, K. Cisneros et al., "Benefits of rituximab combined with intravenous immunoglobulin for desensitization in kidney transplant recipients," Transplantation, vol. 98, no. 3, pp. 312-319, 2014.

[15] A. A. Vo, M. Lukovsky, M. Toyoda et al., "Rituximab and intravenous immune globulin for desensitization during renal transplantation," The New England Journal of Medicine, vol. 359, no. 3, pp. 242-251, 2008.

[16] J. A. Cohen, A. J. Coles, D. L. Arnold et al., "Alemtuzumab versus interferon beta la as first-line treatment for patients with relapsing-remitting multiple sclerosis: a randomised controlled phase 3 trial," The Lancet, vol. 380, no. 9856, pp. 1819-1828, 2012.

[17] M. J. Hanaway, E. S. Woodle, S. Mulgaonkar et al., "Alemtuzumab induction in renal transplantation," The New England Journal of Medicine, vol. 364, no. 20, pp. 1909-1919, 2011.

[18] L. Isidoro, P. Pires, L. Rito, and G. Cordeiro, "Progressive multifocal leukoencephalopathy in a patient with chronic lymphocytic leukaemia treated with alemtuzumab," BMJ Case Reports, vol. 2014, 2014.

[19] N. C. Issa and J. A. Fishman, "Infectious complications of antilymphocyte therapies in solid organ transplantation," Clinical Infectious Diseases, vol. 48, no. 6, pp. 772-786, 2009.

[20] S. I. Martin, F. M. Marty, K. Fiumara, S. P. Treon, J. G. Gribben, and L. R. Baden, "Infectious complications associated with alemtuzumab use for lymphoproliferative disorders," Clinical Infectious Diseases, vol. 43, no. 1, pp. 16-24, 2006.

[21] A. Y. Peleg, S. Husain, E. J. Kwak et al., "Opportunistic infections in 547 organ transplant recipients receiving alemtuzumab, a humanized monoclonal CD-52 antibody," Clinical Infectious Diseases, vol. 44, no. 2, pp. 204-212, 2007.

[22] X. Zhang, H. Huang, S. Han, S. Fu, and L. Wang, "Alemtuzumab induction in renal transplantation: a meta-analysis and systemic review," Transplant Immunology, vol. 27, no. 2-3, pp. 63-68, 2012.

[23] J. Kahwaji, A. Sinha, M. Toyoda et al., "Infectious complications in kidney-transplant recipients desensitized with rituximab and intravenous immunoglobulin," Clinical Journal of the American Society of Nephrology, vol. 6, no. 12, pp. 2894-2900, 2011.

[24] M. Toyoda, D. Thomas, G. Ahn et al., "JC polyomavirus viremia and progressive multifocal leukoencephalopathy in human leukocyte antigen-sensitized kidney transplant recipients desensitized with intravenous immunoglobulin and rituximab," Transplant Infectious Disease, vol. 17, no. 6, pp. 838-847, 2015.

[25] A. A. Vo, A. Peng, M. Toyoda et al., "Use of intravenous immune globulin and rituximab for desensitization of highly HLAsensitized patients awaiting kidney transplantation," Transplantation, vol. 89, no. 9, pp. 1095-1102, 2010. 
[26] A. A. Vo, E. A. Wechsler, J. Wang et al., "Analysis of subcutaneous (SQ) alemtuzumab induction therapy in highly sensitized patients desensitized with IVIG and rituximab," American Journal of Transplantation, vol. 8, no. 1, pp. 144-149, 2008.

[27] D. Barbosa, J. Kahwaji, D. Puliyanda et al., "Polyomavirus BK viremia in kidney transplant recipients after desensitization with IVIG and rituximab," Transplantation, vol. 97, no. 7, pp. 755-761, 2014.

[28] C. Martin-Gandul, N. J. Mueller, M. Pascual, and O. Manuel, "The impact of infection on chronic allograft dysfunction and allograft survival after solid organ transplantation," American Journal of Transplantation, vol. 15, no. 12, pp. 3024-3040, 2015.

[29] P. Reinke, S. Prösch, F. Kern, and H.-D. Volk, "Mechanisms of human cytomegalovirus (HCMV) (re)activation and its impact on organ transplant patients," Transplant Infectious Disease, vol. 1, no. 3, pp. 157-164, 1999.

[30] G. Dieplinger, M. J. Everly, K. P. Briley et al., "Onset and progression of de novo donor-specific anti-human leukocyte antigen antibodies after BK polyomavirus and preemptive immunosuppression reduction," Transplant Infectious Disease, vol. 17, no. 6, pp. 848-858, 2015.

[31] M. Haas, "The revised (2013) Banff classification for antibodymediated rejection of renal allografts: update, difficulties, and future considerations," American Journal of Transplantation, vol. 16, no. 5, pp. 1352-1357, 2016.

[32] M. Haas, B. Sis, L. C. Racusen et al., "Banff 2013 meeting report: inclusion of c4d-negative antibody-mediated rejection and antibody-associated arterial lesions," American Journal of Transplantation, vol. 14, no. 2, pp. 272-283, 2014.

[33] L. C. Racusen, K. Solez, R. B. Colvin et al., "The Banff 97 working classification of renal allograft pathology," Kidney International, vol. 55, no. 2, pp. 713-723, 1999.

[34] M. Toyoda, D. P. Puliyanda, N. Amet et al., "Co-infection of polyomavirus-BK and cytomegalovirus in renal transplant recipients," Transplantation, vol. 80, no. 2, pp. 198-205, 2005.

[35] J. S. Kalpoe, A. C. M. Kroes, M. D. de Jong et al., "Validation of clinical application of cytomegalovirus plasma DNA load measurement and definition of treatment criteria by analysis of correlation to antigen detection," Journal of Clinical Microbiology, vol. 42, no. 4, pp. 1498-1504, 2004.

[36] H. Kimura, M. Morita, Y. Yabuta et al., "Quantitative analysis of Epstein-Barr virus load by using a real-time PCR assay," Journal of Clinical Microbiology, vol. 37, no. 1, pp. 132-136, 1999.

[37] S. Ge, A. Karasyov, A. Sinha et al., "Cytomegalovirus immunity after alemtuzumab induction in desensitized kidney transplant patients," Transplantation, 2016.

[38] M. Toyoda, S. Ge, E. Suviolahti et al., "IFN $\gamma$ production by NK cells from HLA-sensitized patients after in vitro exposure to allo-antigens," Transplant Immunology, vol. 26, no. 2-3, pp. 107112, 2012.

[39] S. Ge, A. Pao, A. Vo et al., "Immunologic parameters and viral infections in patients desensitized with intravenous immunoglobulin and rituximab," Transplant Immunology, vol. 24, no. 3, pp. 142-148, 2011.

[40] R. Radha, S. Jordan, D. Puliyanda et al., "Cellular immune responses to cytomegalovirus in renal transplant recipients," American Journal of Transplantation, vol. 5, no. 1, pp. 110-117, 2005.

[41] B.-H. Shin, S. Ge, J. Mirocha et al., "Regulation of anti-HLA antibody-dependent natural killer cell activation by immunosuppressive agents," Transplantation, vol. 97, no. 3, pp. 294-300, 2014.
[42] L. Tradtrantip, N. Asavapanumas, and A. S. Verkman, "Therapeutic cleavage of anti-aquaporin-4 autoantibody in neuromyelitis optica by an igg-selective proteinase," Molecular Pharmacology, vol. 83, no. 6, pp. 1268-1275, 2013.

[43] R. K. Avery and E. A. Blumberg, "Hypogammaglobulinemia: time to reevaluate?" American Journal of Transplantation, vol. 13, no. 10, pp. 2517-2518, 2013.

[44] S. Heidt, J. Hester, S. Shankar, P. J. Friend, and K. J. Wood, "B cell repopulation after alemtuzumab induction-transient increase in transitional B cells and long-term dominance of naïve B cells," American Journal of Transplantation, vol. 12, no. 7, pp. 17841792, 2012.

[45] H. Lowenstein, A. Shah, A. Chant, and A. Khan, "Different mechanisms of Campath-1H-mediated depletion for CD4+ and CD8+ T cells in peripheral blood," Transplant International, vol. 19, no. 11, pp. 927-936, 2006.

[46] P. Trzonkowski, M. Zilvetti, S. Chapman et al., "Homeostatic repopulation by $\mathrm{CD} 28^{-} \mathrm{CD} 8^{+} \mathrm{T}$ cells in alemtuzumab-depleted kidney transplant recipients treated with reduced immunosuppression," American Journal of Transplantation, vol. 8, no. 2, pp. $338-347,2008$.

[47] S. P. Rao, J. Sancho, J. Campos-Rivera et al., "Human peripheral blood mononuclear cells exhibit heterogeneous CD52 expression levels and show differential sensitivity to alemtuzumab mediated cytolysis," PLoS ONE, vol. 7, no. 6, Article ID e39416, 2012.

[48] D. J. van der Windt, C. Smetanka, C. MacEdo et al., "Investigation of lymphocyte depletion and repopulation using alemtuzumab (Campath-1H) in cynomolgus monkeys," American Journal of Transplantation, vol. 10, no. 4, pp. 773-783, 2010.

[49] R. M. Fleischmann, "Progressive multifocal leukoencephalopathy following rituximab treatment in a patient with rheumatoid arthritis," Arthritis and Rheumatism, vol. 60, no. 11, pp. 32253228, 2009.

[50] M. Mohty, "Mechanisms of action of antithymocyte globulin: T-cell depletion and beyond," Leukemia, vol. 21, no. 7, pp. 13871394, 2007.

[51] J. Sageshima, G. Ciancio, G. Guerra et al., "Prolonged lymphocyte depletion by single-dose rabbit anti-thymocyte globulin and alemtuzumab in kidney transplantation," Transplant Immunology, vol. 25, no. 2-3, pp. 104-111, 2011.

[52] M. Green, "Introduction: infections in solid organ transplantation," American Journal of Transplantation, vol. 13, supplement 4, pp. 3-8, 2013.

[53] N. S. Ejaz, A. R. Shields, R. R. Alloway et al., "Randomized controlled pilot study of B cell-targeted induction therapy in HLA sensitized kidney transplant recipients," American Journal of Transplantation, vol. 13, no. 12, pp. 3142-3154, 2013.

[54] N. Kamar, O. Milioto, B. Puissant-Lubrano et al., "Incidence and predictive factors for infectious disease after rituximab therapy in kidney-transplant patients," American Journal of Transplantation, vol. 10, no. 1, pp. 89-98, 2010.

[55] E. Schadde, A. M. D’Alessandro, S. J. Knechtle et al., "Alemtuzumab induction and triple maintenance immunotherapy in kidney transplantation from donors after cardiac death," Transplant International, vol. 21, no. 7, pp. 625-636, 2008.

[56] K. Chan, D. Taube, C. Roufosse et al., "Kidney transplantation with minimized maintenance: alemtuzumab induction with tacrolimus monotherapy-an open label, randomized trial," Transplantation, vol. 92, no. 7, pp. 774-780, 2011. 
[57] T.-M. Lü, S.-L. Yang, W.-Z. Wu, and J.-M. Tan, “Alemtuzumab induction therapy in highly sensitized kidney transplant recipients," Chinese Medical Journal, vol. 124, no. 5, pp. 664-668, 2011.

[58] V. Appay, P. R. Dunbar, M. Callan et al., "Memory CD8 ${ }^{+}$T cells vary in differentiation phenotype in different persistent virus infections," Nature Medicine, vol. 8, no. 4, pp. 379-385, 2002.

[59] G. Gerna, D. Lilleri, A. Chiesa et al., "Virologic and immunologic monitoring of cytomegalovirus to guide preemptive therapy in solid-organ transplantation," American Journal of Transplantation, vol. 11, no. 11, pp. 2463-2471, 2011.

[60] F. Leone, P. Gigliotti, M. V. Mauro et al., "Early cytomegalovirusspecific T-cell response and estimated glomerular filtration rate identify patients at high risk of infection after renal transplantation," Transplant Infectious Disease, vol. 18, no. 2, pp. 191-201, 2016.

[61] S.-K. Tey, G. A. Kennedy, D. Cromer et al., "Clinical assessment of anti-viral $\mathrm{CD}^{+} \mathrm{T}$ cell immune monitoring using QuantiFERON-CMV ${ }^{\circledR}$ assay to identify high risk allogeneic hematopoietic stem cell transplant patients with CMV infection complications," PLoS ONE, vol. 8, no. 10, Article ID e74744, 2013.

[62] J. W. Gratama, J. W. J. Van Esser, C. H. J. Lamers et al., "Tetramer-based quantification of cytomegalovirus (CMV)-specific CD8+ T lymphocytes in T-cell-depleted stem cell grafts and after transplantation may identify patients at risk for progressive CMV infection," Blood, vol. 98, no. 5, pp. 1358-1364, 2001.

[63] O. Kousin-Ezewu, L. Azzopardi, R. A. Parker et al., "Accelerated lymphocyte recovery after alemtuzumab does not predict multiple sclerosis activity," Neurology, vol. 82, no. 24, pp. 2158-2164, 2014.

[64] A. Zeevi, S. Husain, K. J. Spichty et al., "Recovery of functional memory $\mathrm{T}$ cells in lung transplant recipients following induction therapy with alemtuzumab," American Journal of Transplantation, vol. 7, no. 2, pp. 471-475, 2007.

[65] M. R. Clatworthy, P. J. Friend, R. Y. Calne et al., "Alemtuzumab (CAMPATH-1H) for the treatment of acute rejection in kidney transplant recipients: long-term follow-up," Transplantation, vol. 87, no. 7, pp. 1092-1095, 2009.

[66] S. K. Malek, M. A. Obmann, R. A. Gotoff, M. A. Foltzer, J. E. Hartle, and S. Potdar, "Campath-1H induction and the incidence of infectious complications in adult renal transplantation," Transplantation, vol. 81, no. 1, pp. 17-20, 2006.

[67] S. A. Calarota, A. Chiesa, P. Zelini, G. Comolli, L. Minoli, and F. Baldanti, "Detection of Epstein-Barr virus-specific memory CD4+ $\mathrm{T}$ cells using a peptide-based cultured enzyme-linked immunospot assay," Immunology, vol. 139, no. 4, pp. 533-544, 2013.

[68] D. A. Falco, R. R. Nepomuceno, S. M. Krams et al., "Identification of Epstein-Barr virus-specific $\mathrm{CD}^{+} \mathrm{T}$ lymphocytes in the circulation of pediatric transplant recipients," Transplantation, vol. 74, no. 4, pp. 501-510, 2002.

[69] J. Carbone, “The immunology of posttransplant CMV infection: potential effect of CMV immunoglobulins on distinct components of the immune response to CMV," Transplantation, vol. 100, supplement 3, pp. S11-S18, 2016.

[70] M. Khyatti, P. C. Patel, I. Stefanescu, and J. Menezes, "EpsteinBarr virus (EBV) glycoprotein gp350 expressed on transfected cells resistant to natural killer cell activity serves as a target antigen for EBV-specific antibody-dependent cellular cytotoxicity;" Journal of Virology, vol. 65, no. 2, pp. 996-1001, 1991.
[71] J. Xu, A. Ahmad, M. Blagdon et al., "The Epstein-Barr virus (EBV) major envelope glycoprotein gp350/220-specific antibody reactivities in the sera of patients with different EBVassociated diseases," International Journal of Cancer, vol. 79, no. 5, pp. 481-486, 1998.

[72] E. Sarmiento, N. Lanio, A. Gallego et al., "Immune monitoring of anti cytomegalovirus antibodies and risk of cytomegalovirus disease in heart transplantation," International Immunopharmacology, vol. 9, no. 6, pp. 649-652, 2009.

[73] D. F. Florescu, A. C. Kalil, F. Qiu, C. M. Schmidt, and U. Sandkovsky, "What is the impact of hypogammaglobulinemia on the rate of infections and survival in solid organ transplantation? A meta-analysis," American Journal of Transplantation, vol. 13, no. 10, pp. 2601-2610, 2013.

[74] S. C. Jordan, M. Toyoda, J. Kahwaji, and A. A. Vo, "Clinical aspects of intravenous immunoglobulin use in solid organ transplant recipients," American Journal of Transplantation, vol. 11, no. 2, pp. 196-202, 2011.

[75] M. Green, M. G. Michaels, B. Z. Katz et al., "CMV-IVIG for prevention of Epstein Barr virus disease and posttransplant lymphoproliferative disease in pediatric liver transplant recipients," American Journal of Transplantation, vol. 6, no. 8, pp. 1906-1912, 2006.

[76] N. R. Barsoum, S. Bunnapradist, A. Mougdil, M. Toyoda, A. Vo, and S. C. Jordan, "Treatment of parvovirus B-19 (PV B-19) infection allows for successful kidney transplantation without disease recurrence," American Journal of Transplantation, vol. 2, no. 5, pp. 425-428, 2002.

[77] D. Puliyanda, R. K. Radha, N. Amet, L. Hilo, and S. C. Jordan, "IVIG contains antibodies reactive with polyoma BK virus and may represent a therapeutic option for BK nephropathy," American Journal of Transplantation, vol. 3, article 393, 2003.

[78] C. L. Jacob, L. Lamorte, E. Sepulveda, I. C. Lorenz, A. Gauthier, and M. Franti, "Neutralizing antibodies are unable to inhibit direct viral cell-to-cell spread of human cytomegalovirus," Virology, vol. 444, no. 1-2, pp. 140-147, 2013.

[79] S. B. Cohen, P. Emery, M. W. Greenwald et al., "Rituximab for rheumatoid arthritis refractory to anti-tumor necrosis factor therapy: results of a multicenter, randomized, double-blind, placebo-controlled, phase III trial evaluating primary efficacy and safety at twenty-four weeks," Arthritis \& Rheumatism, vol. 54, no. 9, pp. 2793-2806, 2006.

[80] S. L. Hauser, E. Waubant, D. L. Arnold et al., "B-cell depletion with rituximab in relapsing-remitting multiple sclerosis," The New England Journal of Medicine, vol. 358, no. 7, pp. 676-688, 2008.

[81] J. C. W. Edwards, L. Szczepański, J. Szechiński et al., "Efficacy of B-cell-targeted therapy with rituximab in patients with rheumatoid arthritis," New England Journal of Medicine, vol. 350, no. 25, pp. 2572-2581, 2004.

[82] D. G. Maloney, A. J. Grillo-López, C. A. White et al., "IDECC2B8 (rituximab) anti-CD20 monoclonal antibody therapy in patients with relapsed low-grade non-Hodgkin's lymphoma," Blood, vol. 90, no. 6, pp. 2188-2195, 1997.

[83] B. F. Hoyer, K. Moser, A. E. Hauser et al., "Short-lived plasmablasts and long-lived plasma cells contribute to chronic humoral autoimmunity in NZB/W mice," The Journal of Experimental Medicine, vol. 199, no. 11, pp. 1577-1584, 2004.

[84] M. A. Caligiuri, "Human natural killer cells," Blood, vol. 112, no. 3, pp. 461-469, 2008.

[85] K. Frenzel, J. Lehmann, D. H. Krüger, L. Martin-Parras, L. Uharek, and J. Hofmann, "Combination of immunoglobulins 
and natural killer cells in the context of CMV and EBV infection," Medical Microbiology and Immunology, vol. 203, no. 2, pp. 115-123, 2014.

[86] M. R. Betts, J. M. Brenchley, D. A. Price et al., "Sensitive and viable identification of antigen-specific $\mathrm{CD}^{+} \mathrm{T}$ cells by a flow cytometric assay for degranulation," Journal of Immunological Methods, vol. 281, no. 1-2, pp. 65-78, 2003.

[87] M. A. Cooper, T. A. Fehniger, and M. A. Caligiuri, "The biology of human natural killer-cell subsets," Trends in Immunology, vol. 22, no. 11, pp. 633-640, 2001.

[88] J. N. Beilke and R. G. Gill, "Frontiers in nephrology: the varied faces of natural killer cells in transplantation-contributions to both allograft immunity and tolerance," Journal of the American Society of Nephrology, vol. 18, no. 8, pp. 2262-2267, 2007.

[89] W. M. Yokoyama and B. F. M. Plougastel, "Immune functions encoded by the natural killer gene complex," Nature Reviews Immunology, vol. 3, no. 4, pp. 304-316, 2003.

[90] J. G. O'Leary, M. Goodarzi, D. L. Drayton, and U. H. von Andrian, "T cell- and B cell-independent adaptive immunity mediated by natural killer cells," Nature Immunology, vol. 7, no. 5, pp. 507-516, 2006.

[91] S. Paust and U. H. von Andrian, "Natural killer cell memory," Nature Immunology, vol. 12, no. 6, pp. 500-508, 2011.

[92] L. Winstedt, S. Järnum, E. A. Nordahl et al., "Complete removal of extracellular IgG antibodies in a randomized doseescalation phase I study with the bacterial enzyme IdeS-a novel therapeutic opportunity," PLoS ONE, vol. 10, no. 7, Article ID e0132011, 2015.

[93] S. Lopez-Vergès, J. M. Milush, B. S. Schwartz et al., "Expansion of a unique $\mathrm{CD} 57^{+} \mathrm{NKG} 2 \mathrm{Chi}$ natural killer cell subset during acute human cytomegalovirus infection," Proceedings of the National Academy of Sciences of the United States of America, vol. 108, no. 36, pp. 14725-14732, 2011.

[94] H. Venema, A. P. Van Den Berg, C. Van Zanten, W. J. Van Son, M. Van Der Giessen, and T. Hauw, "Natural killer cell responses in renal transplant patients with cytomegalovirus infection," Journal of Medical Virology, vol. 42, no. 2, pp. 188-192, 1994.

[95] Z. Wu, C. Sinzger, G. Frascaroli et al., "Human cytomegalovirusinduced NKG2C(hi) CD57(hi) natural killer cells are effectors dependent on humoral antiviral immunity," Journal of Virology, vol. 87, no. 13, pp. 7717-7725, 2013.

[96] D. W. Hendricks, H. H. Balfour Jr., S. K. Dunmire, D. O. Schmeling, K. A. Hogquist, and L. L. Lanier, "Cutting edge: $\mathrm{NKG} 2 \mathrm{C}^{\mathrm{hi}} \mathrm{CD} 57^{+} \mathrm{NK}$ cells respond specifically to acute infection with cytomegalovirus and not Epstein-Barr virus," The Journal of Immunology, vol. 192, no. 10, pp. 4492-4496, 2014.

[97] M. López-Botet, A. Muntasell, and C. Vilches, "The CD94/ NKG2C+ NK-cell subset on the edge of innate and adaptive immunity to human cytomegalovirus infection," Seminars in Immunology, vol. 26, no. 2, pp. 145-151, 2014.

[98] B. E. Griffin and S.-A. Xue, "Epstein-Barr virus infections and their association with human malignancies: some key questions," Annals of Medicine, vol. 30, no. 3, pp. 249-259, 1998.

[99] D. A. Thorley-Lawson, E. M. Miyashita, and G. Khan, "EpsteinBarr virus and the B cell: that's all it takes," Trends in Microbiology, vol. 4, no. 5, pp. 204-208, 1996.

[100] D. M. Burns, S. Rana, E. Martin et al., "Greatly reduced risk of EBV reactivation in rituximab-experienced recipients of alemtuzumab-conditioned allogeneic HSCT,' Bone Marrow Transplantation, vol. 51, no. 6, pp. 825-832, 2016.
[101] B. N. Savani, P. R. Pohlmann, M. Jagasia et al., "Does peritransplantation use of rituximab reduce the risk of EBV reactivation and PTLPD?” Blood, vol. 113, no. 24, pp. 6263-6264, 2009.

[102] T. Schachtner and P. Reinke, "Pretransplant prophylactic rituximab to prevent Epstein-Barr virus (EBV) viremia in EBVseronegative kidney transplant recipients from EBV-seropositive donors: Results of A Pilot Study," Transplant Infectious Disease, vol. 18, no. 6, pp. 881-888, 2016.

[103] G. Hahn, R. Jores, and E. S. Mocarski, "Cytomegalovirus remains latent in a common precursor of dendritic and myeloid cells," Proceedings of the National Academy of Sciences of the United States of America, vol. 95, no. 7, pp. 3937-3942, 1998.

[104] J. Taylor-Wiedeman, J. G. P. Sissons, L. K. Borysiewicz, and J. H. Sinclair, "Monocytes are a major site of persistence of human cytomegalovirus in peripheral blood mononuclear cells," Journal of General Virology, vol. 72, no. 9, pp. 2059-2064, 1991.

[105] A. Egli, S. Binggeli, S. Bodaghi et al., "Cytomegalovirus and polyomavirus BK posttransplant," Nephrology Dialysis Transplantation, vol. 22, supplement 8, pp. viii72-viii82, 2007.

[106] C. N. Kotton, D. Kumar, A. M. Caliendo et al., "Updated international consensus guidelines on the management of cytomegalovirus in solid-organ transplantation," Transplantation, vol. 96, no. 4, pp. 333-360, 2013.

[107] T. Fehr, P. E. Cippà, and N. J. Mueller, "Cytomegalovirus post kidney transplantation: prophylaxis versus pre-emptive therapy?" Transplant International, vol. 28, no. 12, pp. 1351-1356, 2015.

[108] C. N. Kotton, "CMV: prevention, diagnosis and therapy," American Journal of Transplantation, vol. 13, supplement 3, pp. 24-40, 2013.

[109] S. Kowalsky, R. Arnon, and R. Posada, "Prevention of cytomegalovirus following solid organ transplantation: a literature review," Pediatric Transplantation, vol. 17, no. 6, pp. 499509, 2013.

[110] M. Slifkin, S. Doron, and D. R. Snydman, "Viral prophylaxis in organ transplant patients," Drugs, vol. 64, no. 24, pp. 2763-2792, 2004.

[111] E. W. Gelfand, "Intravenous immune globulin in autoimmune and inflammatory diseases," New England Journal of Medicine, vol. 367, no. 21, pp. 2015-2025, 2012.

[112] L. Gilardin, J. Bayry, and S. V. Kaveri, "Intravenous immunoglobulin as clinical immune-modulating therapy," CMAJ, vol. 187, no. 4, pp. 257-264, 2015.

[113] S. C. Jordan, A. Vo, S. Bunnapradist et al., "Intravenous immune globulin treatment inhibits crossmatch positivity and allows for successful transplantation of incompatible organs in livingdonor and cadaver recipients," Transplantation, vol. 76, no. 4, pp. 631-636, 2003.

[114] M. Toyoda, A. Pao, A. Petrosian, and S. C. Jordan, "Pooled human gammaglobulin modulates surface molecule expression and induces apoptosis in human B cells," American Journal of Transplantation, vol. 3, no. 2, pp. 156-166, 2003.

[115] M. Toyoda, X. Zhang, A. Petrosian, O. A. Galera, S.-J. Wang, and S. C. Jordan, "Modulation of immunoglobulin production and cytokine mRNA expression in peripheral blood mononuclear cells by intravenous immunoglobulin," Journal of Clinical Immunology, vol. 14, no. 3, pp. 178-189, 1994.

[116] M. Toyoda, X.-M. Zhang, A. Petrosian, K. Wachs, A. Moudgil, and S. C. Jordan, "Inhibition of allospecific responses in the mixed lymphocyte reaction by pooled human gamma-globulin," Transplant Immunology, vol. 2, no. 4, pp. 337-341, 1994. 
[117] F. Cainelli and S. Vento, "Infections and solid organ transplant rejection: a cause-and-effect relationship?" Lancet Infectious Diseases, vol. 2, no. 9, pp. 539-549, 2002.

[118] S. Sagedal, K. P. Nordal, A. Hartmann et al., "The impact of cytomegalovirus infection and disease on rejection episodes in renal allograft recipients," American Journal of Transplantation, vol. 2, no. 9, pp. 850-856, 2002.

[119] M. Stern, H. Hirsch, A. Cusini et al., "Cytomegalovirus serology and replication remain associated with solid organ graft rejection and graft loss in the era of prophylactic treatment," Transplantation, vol. 98, no. 9, pp. 1013-1018, 2014. 


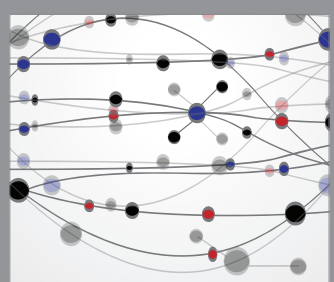

The Scientific World Journal
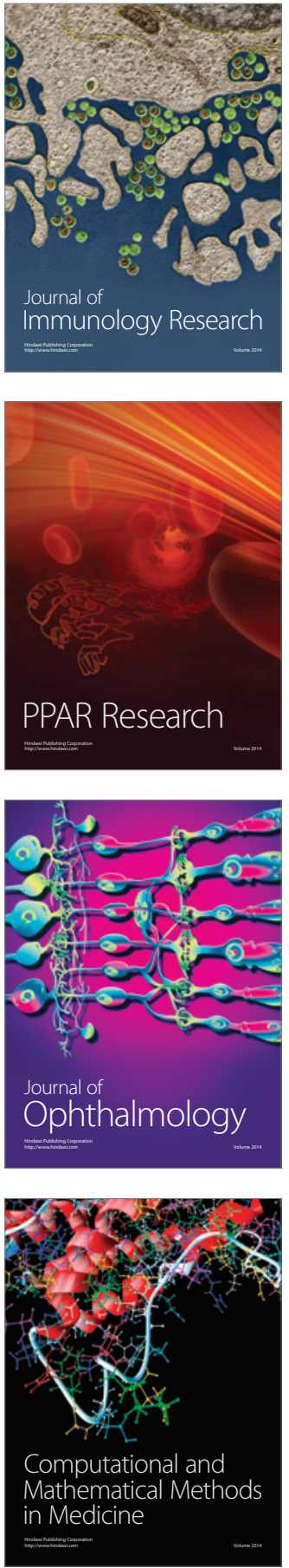

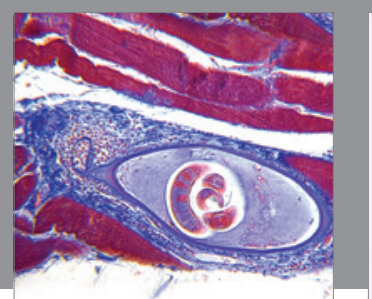

Gastroenterology Research and Practice
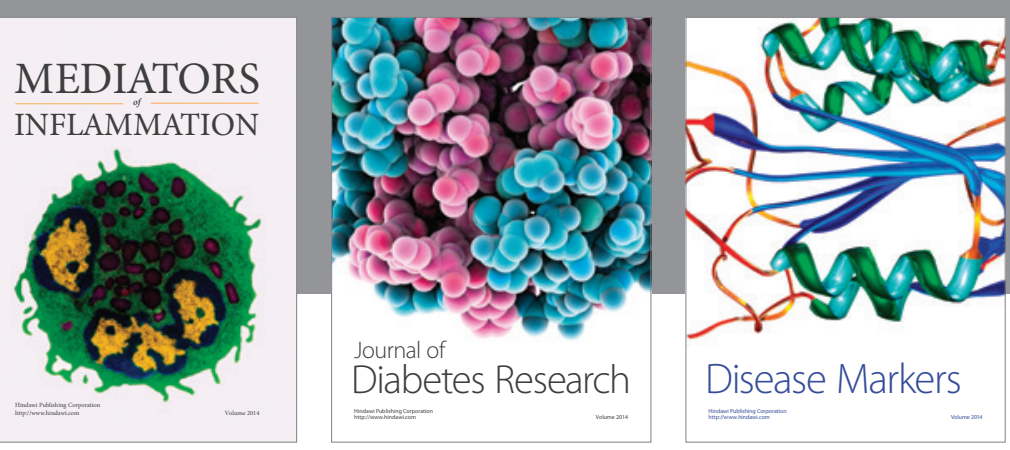

Disease Markers

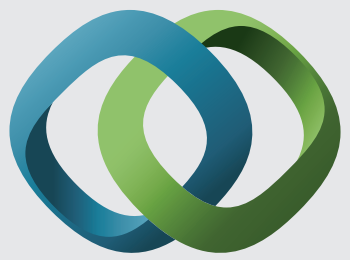

\section{Hindawi}

Submit your manuscripts at

https://www.hindawi.com
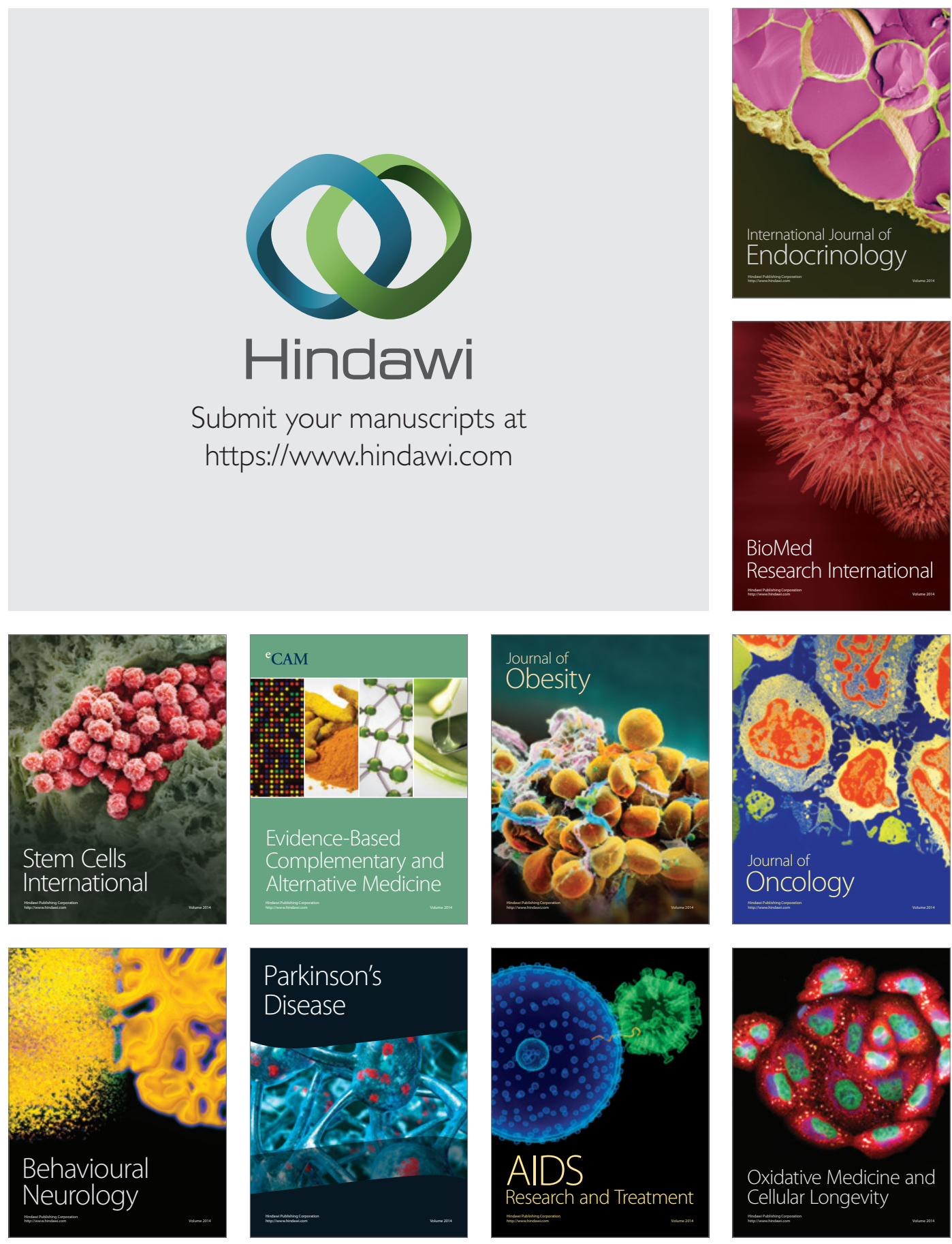